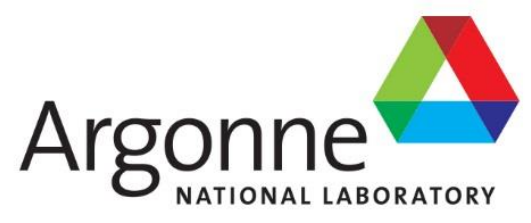

\title{
Uranyl Sulfate Irradiations at the Van de Graaff: A Means to Combat Uranyl Peroxide Precipitation
}

Nuclear Engineering Division 


\begin{abstract}
About Argonne National Laboratory
Argonne is a U.S. Department of Energy laboratory managed by UChicago Argonne, LLC under contract DE-AC02-06CH11357. The Laboratory's main facility is outside Chicago, at 9700 South Cass Avenue, Argonne, Illinois 60439. For information about Argonne and its pioneering science and technology programs, see www.anl.gov.
\end{abstract}

\title{
DOCUMENT AVAILABILITY
}

Online Access: U.S. Department of Energy (DOE) reports produced after 1991 and a growing number of pre-1991 documents are available free via DOE's SciTech Connect (http://www.osti.gov/scitech/).

Reports not in digital format may be purchased by the public from the National Technical Information Service (NTIS):

U.S. Department of Commerce

National Technical Information Service

5301 Shawnee Road

Alexandria, VA 22312

www.ntis.gov

Phone: (800) 553-NTIS (6847) or (703) 605-6000

Fax: (703) 605-6900

Email: orders@ntis.gov

Reports not in digital format are available to DOE and DOE contractors from:

U.S. Department of Energy

Office of Scientific and Technical Information

P.O. Box 62

Oak Ridge, TN 37831-0062

\section{Disclaimer}

This report was prepared as an account of work sponsored by an agency of the United States Government. Neither the United States Government nor any agency thereof, nor UChicago Argonne, LLC, nor any of their employees or officers, makes any warranty, express or implied, or assumes any legal liability or responsibility for the accuracy, completeness, or usefulness of any information, apparatus, product, or process disclosed, or represents that its use would not infringe privately owned rights. Reference herein to any specific commercial product, process, or service by trade name, trademark, manufacturer, or otherwise, does not necessarily constitute or imply its endorsement, recommendation, or favoring by the United States Government or any agency thereof. The views and opinions of document authors expressed herein do not necessarily state or reflect those of the United States Government or any agency thereof, Argonne National Laboratory, or UChicago Argonne, LLC. 


\section{Uranyl Sulfate Irradiations at the Van de Graaff: A Means to Combat Uranyl Peroxide Precipitation}

by

Amanda J. Youker, Michael Kalensky, Kevin J. Quigley, Thomas Brossard, Sergey D. Chemerisov, and George F. Vandegrift

Nuclear Engineering Division, Argonne National Laboratory

May 2017 



\section{CONTENTS}

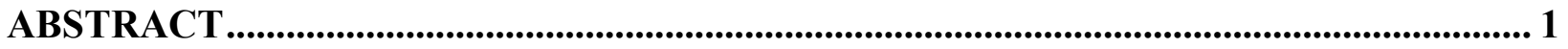

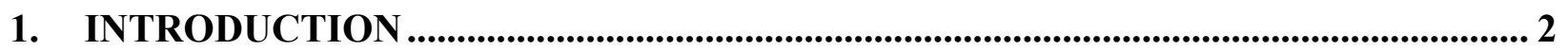

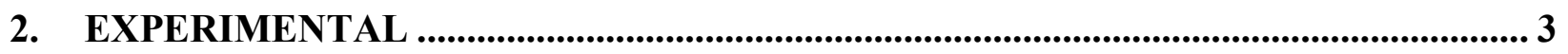

2.1 Preparation of Uranyl Sulfate Solutions................................................................ 3

2.2 Peroxide Concentration Measurements ........................................................................ 3

2.3 Van de Graaff Operation and Oxalic Acid Dosimetry .......................................... 3

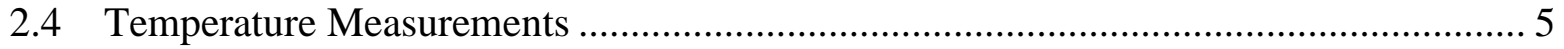

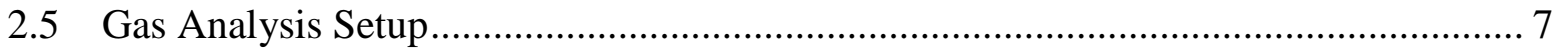

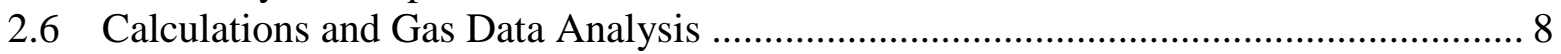

2.7 Apparent Steady-state Determination ......................................................... 9

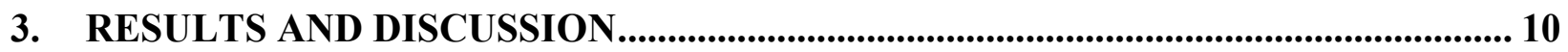

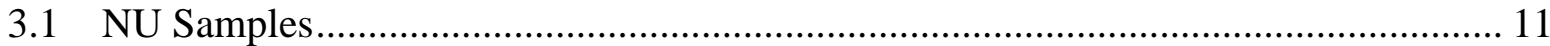

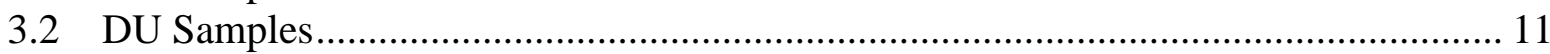

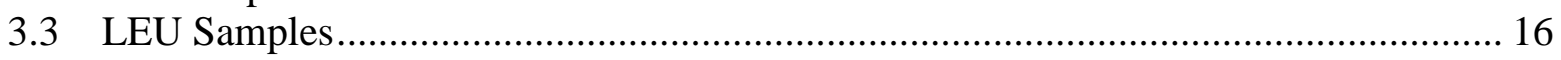

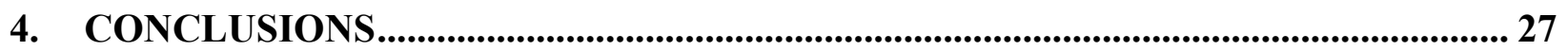

ACKNOWLEDGEMENTS ..................................ERROR! BOOKMARK NOT DEFINED.

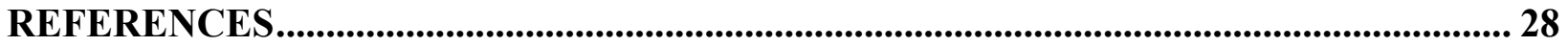

\section{FIGURES}

1 Dose on a $2.0 \mathrm{~mL}$ sample shown as Mrad versus $\mu \mathrm{A}^{*}$ min. .........................................

2 Dose on $0.5 \mathrm{~mL}$ sample shown as Mrad versus $\mu \mathrm{A}^{*}$ min. ............................................4

3 A typical LEU sample where precipitation occurred during irradiation. ...........................5

4 Sample temperature $\left({ }^{\circ} \mathrm{C}\right)$ versus Van de Graaff current $(\mu \mathrm{A})$. ....................................6

5 Experimental design for the Van de Graaff irradiations. ....................................................

6 Experimental setup for irradiations at the Van de Graaff.............................................

7 Gas generation and Van de Graaff current as a function of time for NU sample irradiated without additional hydrogen peroxide before irradiation (12/12/16).

8a Gas generation and Van de Graaff current as a function of time for NU experiment (11/17/16), which had a low initial hydrogen peroxide concentration added and no precipitation. 


\section{FIGURES (CONT.)}

8b Total $\mu$ moles of gas and Van de Graaff current as a function of time for NU experiment (11/17/16), which had a low initial hydrogen peroxide concentration added and no precipitation

9 Gas generation and Van de Graaff current as a function of time for NU experiment (11/29/16), which had a low initial peroxide concentration and delayed precipitation........15

10 Gas generation and Van de Graaff current as a function of time for NU experiment $(11 / 21 / 16)$, which had a high initial peroxide concentration and precipitate present from the start.

11 Gas generation and Van de Graaff current as a function of time for DU experiment $(12 / 6 / 16)$, which had nitrate and a low initial hydrogen peroxide concentration added and no precipitation.

12 Gas generation and Van de Graaff current as a function of time for sample irradiated on $12 / 20 / 16$.

13 Gas generation and Van de Graaff current as a function of time for sample irradiated on $3 / 9 / 17$.

14 Gas generation and Van de Graaff current as a function of time for sample irradiated on $3 / 8 / 17$.

15 Gas generation and Van de Graaff current as a function of time for sample irradiated on $01 / 25 / 17$.

16 Gas generation and Van de Graaff current as a function of time for sample irradiated on $01 / 30 / 17$.

17 Gas generation and Van de Graaff current as a function of time for sample irradiated on $02 / 02 / 17$.

18 Gas generation and Van de Graaff current as a function of time for sample irradiated on $02 / 06 / 17$.

19 Gas generation and Van de Graaff current as a function of time for sample irradiated on $02 / 09 / 17$.

20 Initial gas production of solutions with different composition. 


\section{TABLES}

1 Sample temperature data for various Van de Graaff current and bath temperature with

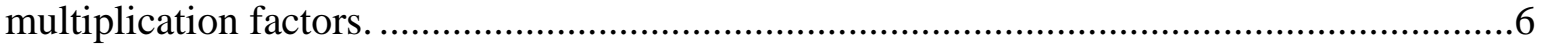

2 Solutions that were irradiated at the Van de Graff. .......................................................10

3 NU and DU samples irradiated at the Van de Graaff accelerator...................................12

4 Results for LEU samples irradiated at the Van de Graaff accelerator (from 12/15/16

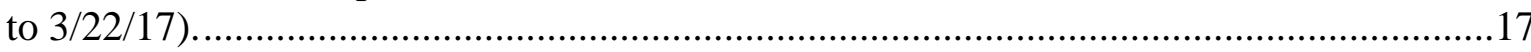

5 Results for LEU samples with additional catalysts irradiated at the Van de Graaff accelerator (from 1/25/17 to $2 / 2 / 17$ ) ............................................................................22

6 Additional LEU samples irradiated at the Van de Graaff accelerator (from 2/6/17 to 2/13/17).....

7 Timed LEU samples that were irradiated at the Van de Graaff at $20 \mu \mathrm{A}$ current (from $2 / 21 / 17$ to $2 / 28 / 17$ ). 
This page intentionally left blank. 


\begin{abstract}
ANL/NE-17/17
Uranyl Sulfate Irradiations at the Van de Graaff: A Means to Combat Uranyl Peroxide Precipitation

Amanda J. Youker, Michael Kalensky, Kevin J. Quigley, Thomas Brossard, Sergey D. Chemerisov, and George F. Vandegrift
\end{abstract}

May 24, 2017

Argonne National Laboratory

Nuclear Engineering Division

\begin{abstract}
As part of an effort to support SHINE Medical Technologies in developing a process to produce Mo-99 by neutron-induced fission, a series of irradiation experiments was performed with a $3 \mathrm{MeV}$ Van de Graaff accelerator to generate high radiation doses in $0.5-2 \mathrm{~mL}$ uranyl sulfate solutions. The purpose was to determine what conditions result in uranyl peroxide precipitation and what can be done to prevent its formation. The effects of temperature, dose rate, uranium concentration, and the addition of known catalysts for the destruction of peroxide were determined.

In these experiments, uranyl peroxide precipitation was observed in natural uranium and low-enriched uranium samples irradiated at the Van de Graaff accelerator. Precipitation was not observed in irradiated depleted uranium samples due to the presence of nitrate in solution. It was determined that a catalyst of at least 200 ppm Fe ${ }^{2+}, 250 \mathrm{ppm} \mathrm{Fe}^{3+}$, or $100 \mathrm{ppm} \mathrm{Fe}^{2+}$ with $100 \mathrm{ppm} \mathrm{Cu}^{2+}$ was needed to prevent precipitation under the given test conditions. Corrosion, which adds metal ions, may take place in the Mo-99 production system, but the addition of a metal ion catalyst is necessary to prevent precipitation. Peroxide destruction was found to increase with increasing temperature, but temperature cannot be used to combat precipitation because a significant temperature gradient is expected in the Mo-99 target vessel and the uranyl sulfate solution will be stored at room temperature while not being irradiated.
\end{abstract}




\section{INTRODUCTION}

Argonne National Laboratory (Argonne) is assisting a potential domestic Mo-99 producer, SHINE Medical Technologies, as part of the National Nuclear Security Administration's (NNSA) Office of Material, Management, and Minimization $\left(\mathrm{M}^{3}\right)$ program in the development of a domestic Mo-99 production pathway that does not use highly enriched uranium (HEU). The process proposed by SHINE would produce Mo-99 by neutron-induced fission of a low enriched uranium (LEU) solution as uranyl sulfate in a subcritical assembly.

One potential technical difficulty with using uranyl sulfate is the precipitation of uranyl peroxide (can be written as $\mathrm{UO}_{2} \mathrm{O}_{2} \cdot \mathrm{nH}_{2} \mathrm{O}$ or $\mathrm{UO}_{4} \cdot \mathrm{nH}_{2} \mathrm{O}$ ). Through a series of reactions, hydrogen peroxide is generated in solution by the radiolysis of water, which can react with the uranyl ion to form a uranyl peroxide precipitate [1-3]. Uranyl-peroxide precipitation must be avoided for safe production of Mo-99 during the proposed process. Equation 1 shows the reaction of uranium and hydrogen peroxide in solution to form the precipitate:

$$
\mathrm{UO}_{2}{ }^{2+}+\mathrm{H}_{2} \mathrm{O}_{2}+\mathrm{n} \mathrm{H}_{2} \mathrm{O} \leftrightarrow \downarrow \mathrm{UO}_{2} \mathrm{O}_{2} \cdot \mathrm{nH}_{2} \mathrm{O}(\mathrm{s})+2 \mathrm{H}^{+}
$$

Varying amounts of hydrogen peroxide were added to select uranyl sulfate samples prior to irradiation until the solubility limit of uranyl peroxide was reached. These samples were irradiated, and it was observed that uranyl peroxide was destroyed by high temperatures and radiolysis. Two mechanisms have been proposed by Silverman et al for the destruction of uranyl peroxide: one is given by equations 2 and 3, and the other by equations 4 and 5 [4].

$$
\begin{aligned}
& \mathrm{UO}_{2} \mathrm{O}_{2} \cdot 2 \mathrm{H}_{2} \mathrm{O}(\mathrm{s})+2 \mathrm{H}^{+} \rightarrow \mathrm{UO}_{2}{ }^{2+}+\mathrm{H}_{2} \mathrm{O}_{2} \\
& \mathrm{H}_{2} \mathrm{O}_{2} \rightarrow \mathrm{H}_{2} \mathrm{O}+1 / 2 \mathrm{O}_{2} \\
& \mathrm{UO}_{2} \mathrm{O}_{2} \rightarrow \mathrm{UO}_{3}+1 / 2 \mathrm{O}_{2} \\
& \mathrm{UO}_{3}+2 \mathrm{H}^{+} \rightarrow \mathrm{UO}_{2}{ }^{2+}+\mathrm{H}_{2} \mathrm{O}
\end{aligned}
$$

A series of irradiation experiments was performed with a $3 \mathrm{MeV}$ Van de Graaff accelerator to generate high radiation doses in $0.5-2 \mathrm{~mL}$ uranyl-sulfate solutions. The purpose of this set of experiments was to determine (1) what conditions result in uranyl-peroxide precipitation and (2) what can be done to prevent its formation. We examined the effects of temperature, dose rate, uranium concentration, and the addition of known catalysts for the destruction of peroxide. Additionally, three different solutions were irradiated with different metal ions and different uranium enrichments and, therefore, different compositions of impurities. Each solutions contained one of the following: depleted uranium (DU) (0.22\% U-235), natural uranium (NU) (0.7\% U-235), or LEU (19.8\% U-235). The composition

of radiolytically generated gases evolved because of electron bombardment of the uranyl sulfate solutions was analyzed. 


\section{EXPERIMENTAL}

\subsection{Preparation of Uranyl Sulfate Solutions}

Two different methods were used for the preparation of uranyl sulfate. For the DU solutions, uranium metal was dissolved in $8 \mathrm{M} \mathrm{HNO}_{3}$ to form uranyl nitrate, and heat and sulfuric acid were used to drive off nitrate and convert it to uranyl sulfate [4]. For the NU and LEU solutions, uranium metal was oxidized to $\mathrm{U}_{3} \mathrm{O}_{8}$ and dissolved in a mixture of hydrogen peroxide and sulfuric acid with heat [5].

\subsection{Peroxide Concentration Measurements}

Samples were analyzed for peroxide approximately 20 minutes post-irradiation using an indirect means of analysis that measures the decrease in absorbance at $628 \mathrm{~nm}$ for toluidine blue [6]. An aliquot of the irradiated solution (10-200 $\mu \mathrm{L})$ was contacted with an excess of potassium iodide in the presence of hydrochloric acid, toluidine blue, and sodium acetate. When hydrogen peroxide is present in solution, it oxidizes the iodide to iodine while bleaching the toluidine blue in acidic solution. The amount of free iodine is directly proportional to the peroxide concentration in solution. For some of the samples containing metal catalysts, sodium fluoride was added because certain metal ions, such as Fe, can interfere with the analysis [6].

\subsection{Van de Graaff Operation and Oxalic Acid Dosimetry}

The low-energy ( $3 \mathrm{MeV}$ ) Van de Graaff accelerator provides the capability of delivering high levels of electron/photon dose rates without creating activation and handling hazards for the irradiated materials. Dose rates were determined by oxalic acid dosimetry for the direct electron beam irradiations performed to study peroxide formation in uranyl sulfate solutions [7]. Figure 1 shows oxalic acid dosimetry results obtained for this set of experiments using a $2 \mathrm{~mL}$ sample volume. Oxalic acid dosimetry measurements were repeated for the $0.5 \mathrm{~mL}$ samples and are shown in Figure 2. In these figures, $y=$ dose $(\mathrm{Mrad})$, and $\mathrm{x}=$ Van de Graaff current $(\mu \mathrm{A})$. The dose delivered into a sample was calculated from equation 6 :

$$
\operatorname{Mrad}=\text { Slope } \times \mu \mathrm{A} \times \text { Time interval }(\min )
$$




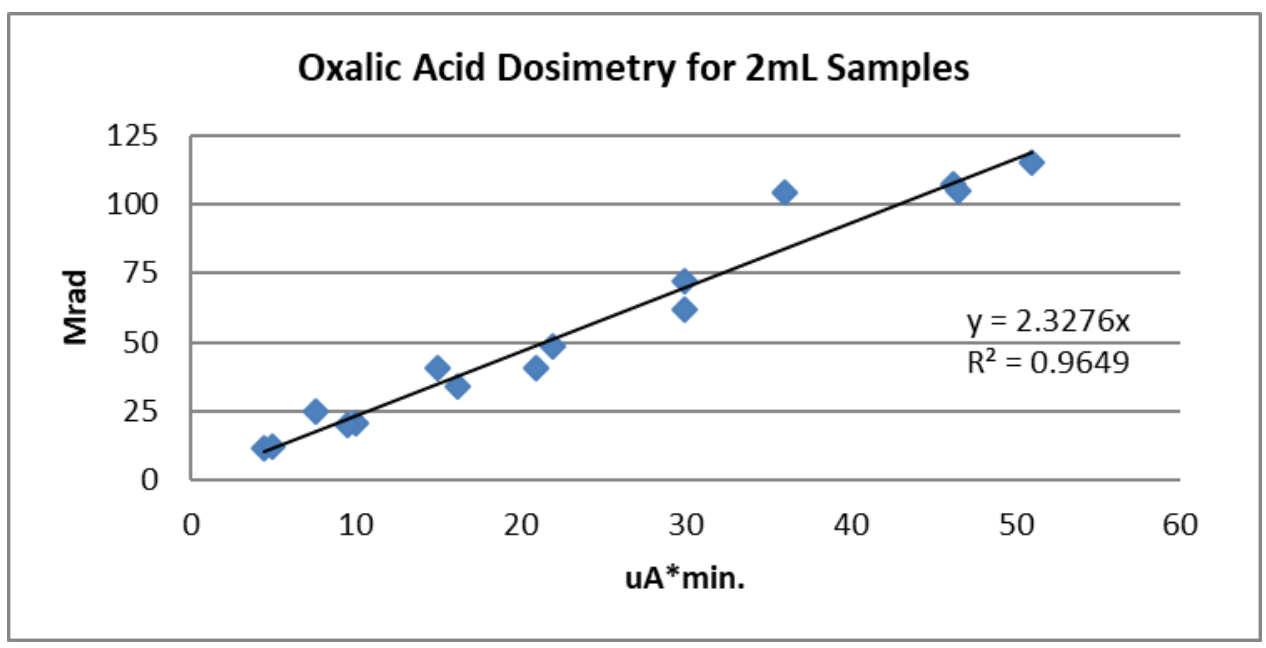

FIGURE 1. Dose on a $2.0 \mathrm{~mL}$ sample shown as Mrad versus $\mu \mathrm{A} *$ min.

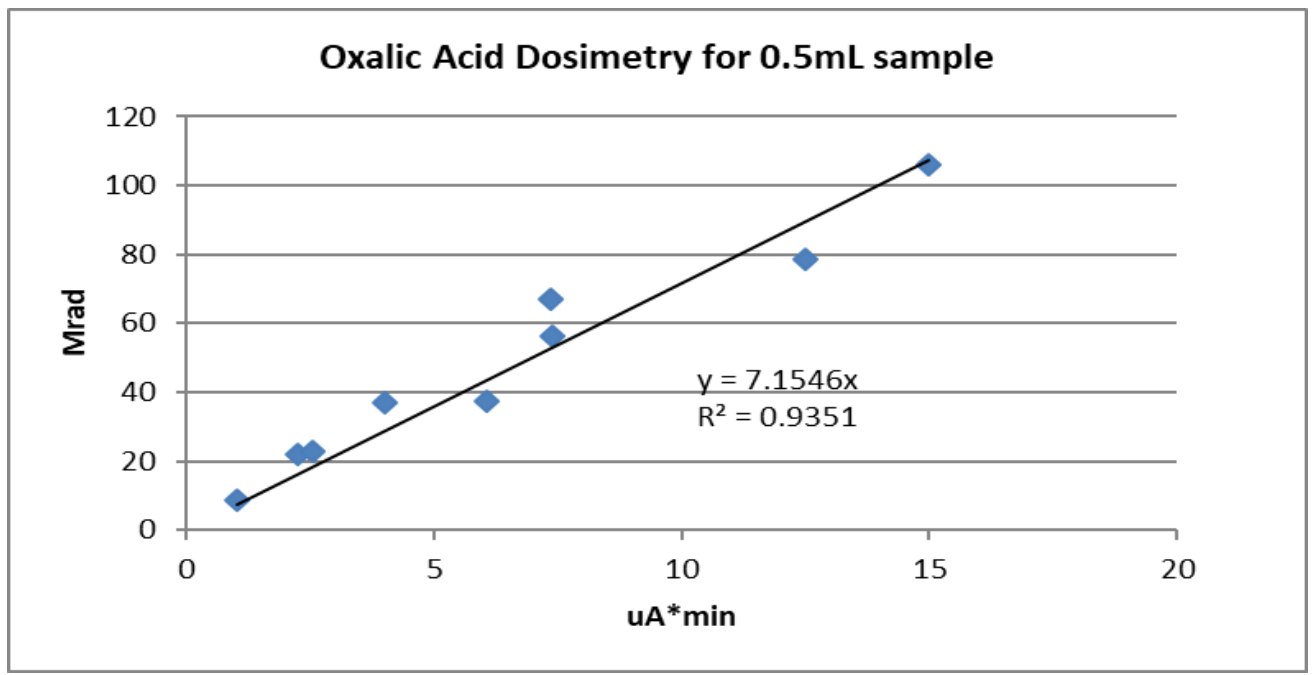

FIGURE 2. Dose on $0.5 \mathrm{~mL}$ sample shown as Mrad versus $\mu \mathrm{A}^{*}$ min.

The Van de Graaff beam can be used in pulse mode or direct current (DC) mode, with pulse widths of 5, 12, 25, 55, and 100 nanoseconds. The frequency is adjustable from 1 to $720 \mathrm{~Hz}$. These experiments were all performed in the DC mode to keep the dose rates uniform throughout the samples. Samples were irradiated in a sample holder mounted directly in front of the beam window. The sample was temperature controlled by water from a bath that circulates around the holder. The temperature was varied in this series of experiments in an effort to find a correlation between temperature and precipitation. Figure 3 shows an example of a sample where precipitation occurred. Prior to analysis, the sample was centrifuged, and the supernatant was used for peroxide analysis. 


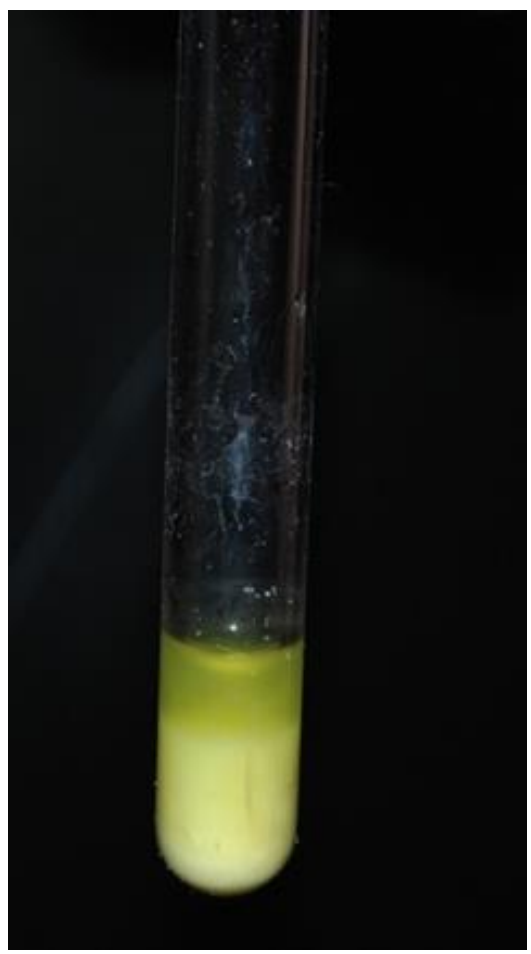

FIGURE 3. A typical LEU sample where precipitation occurred during irradiation.

\subsection{Temperature Measurements}

Sample temperature was determined in several ways. Since sample temperatures varied as a function of dose rate and sample size, temperature measurements were conducted for different Van de Graaff beam currents, bath temperature settings, and sample sizes. For most samples, a linear relationship between the current and sample temperature was used (see Figure 4). A few of the samples were irradiated at different power and bath settings so their temperatures were determined individually (Table 1).

Figure 4 shows the sample temperature data for a $2 \mathrm{~mL}$ sample with the chiller set to $5^{\circ} \mathrm{C}$. From these data, the relationship between the sample temperature and the Van de Graff current $(\mu \mathrm{A})$ was determined, where $\mathrm{y}=$ sample temperature $\left({ }^{\circ} \mathrm{C}\right)$, and $\mathrm{x}=$ Van de Graaff current $(\mu \mathrm{A})$. Equation 7 was used to calculate the sample temperature:

$$
y=2.3818 x+19.412
$$




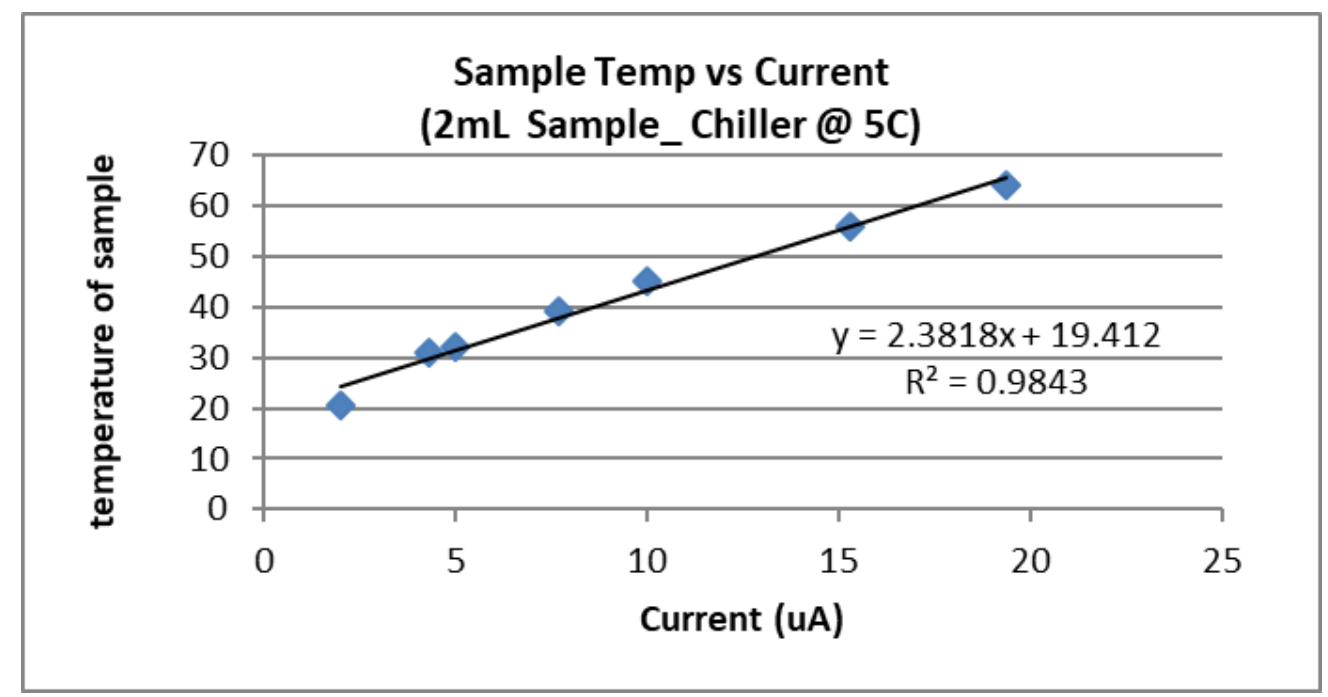

FIGURE 4. Sample temperature $\left({ }^{\circ} \mathrm{C}\right)$ versus Van de Graaff current $(\mu \mathrm{A})$.

Table 1 shows temperature data for the 0.5 and $2.0 \mathrm{~mL}$ samples at various bath temperatures and Van de Graaff currents. The relationship between the sample temperature and Van de Graaff current was determined to obtain a multiplication factor for the different bath temperatures. Equation 8 shows that the multiplication factor is calculated by subtracting the sample temperature $\left({ }^{\circ} \mathrm{C}\right)$ from the initial bath temperature $\left({ }^{\circ} \mathrm{C}\right)$, then dividing by the Van de Graaf current $(\mu \mathrm{A})$ :

Multiplication Factor $=\left[\right.$ Sample $\left({ }^{\circ} \mathrm{C}\right)-$ Bath $\left.\left({ }^{\circ} \mathrm{C}\right)\right] \div$ Current $(\mu \mathrm{A})$

Equation 9 was used to estimate the sample temperature from the bath and current values:

Sample $\left({ }^{\circ} \mathrm{C}\right)=[$ Current $(\mu \mathrm{A}) \times$ Multiplication Factor $]+$ Bath $\left({ }^{\circ} \mathrm{C}\right)$

TABLE 1. Sample temperature data for various Van de Graaff current and bath temperature with multiplication factors.

\begin{tabular}{|c|c|c|c|c|}
\hline $\begin{array}{c}\text { Sample Size } \\
(\mathrm{mL})\end{array}$ & $\begin{array}{c}\text { Bath } \\
\text { Temperature } \\
\left({ }^{\circ} \mathrm{C}\right)\end{array}$ & $\begin{array}{c}\text { Van de Graff } \\
\text { Current }(\mu \mathrm{A})\end{array}$ & $\begin{array}{c}\text { Sample } \\
\text { Temperature }\left({ }^{\circ} \mathrm{C}\right)\end{array}$ & Factor \\
\hline 0.5 & 5.8 & 1.0 & 11.6 & 5.6 \\
\hline 0.5 & 15.8 & 0.9 & 21.1 & 5.6 \\
\hline 0.5 & 20.5 & 0.9 & 25.8 & 6.1 \\
\hline 0.5 & 25.0 & 1.0 & 29.6 & 4.6 \\
\hline 0.5 & 53.7 & 1.0 & 55.2 & 1.5 \\
\hline 0.5 & 5.8 & 5.0 & 34.2 & 5.7 \\
\hline 2.0 & 20.5 & 20.5 & 81.7 & 3.0 \\
\hline
\end{tabular}




\subsection{Gas Analysis Setup}

Figure 5 shows a flow diagram of the experimental setup. A helium/argon cylinder provided a sweep gas for the experiment. A calibrated OMEGA FMA 5400-ST Mass Flow controller was used to regulate the flow of the sweep gas. A calibrated OMEGA MMA030V10H4C0T3A5CE pressure transducer was used to monitor the pressure at the outlet of the sweep gas, which was connected with stainless steel tubing to the inlet of a quartz vial containing the uranyl sulfate solution. The vial was located inside a water-cooled sample holder at the end of the Van de Graaff beamline. Stainless steel tubing connected the outlet of the vial to a Residual Gas Analyzer (RGA) (Pfeiffer OMNI-STAR GSD320) equipped with a 1-200 AMU PrismaPlus QMG220 mass spectrometer. A calibrated OMEGA MMA030V10H4C0T3A5CE pressure transducer monitored the analytical pressure of the sweep gas.

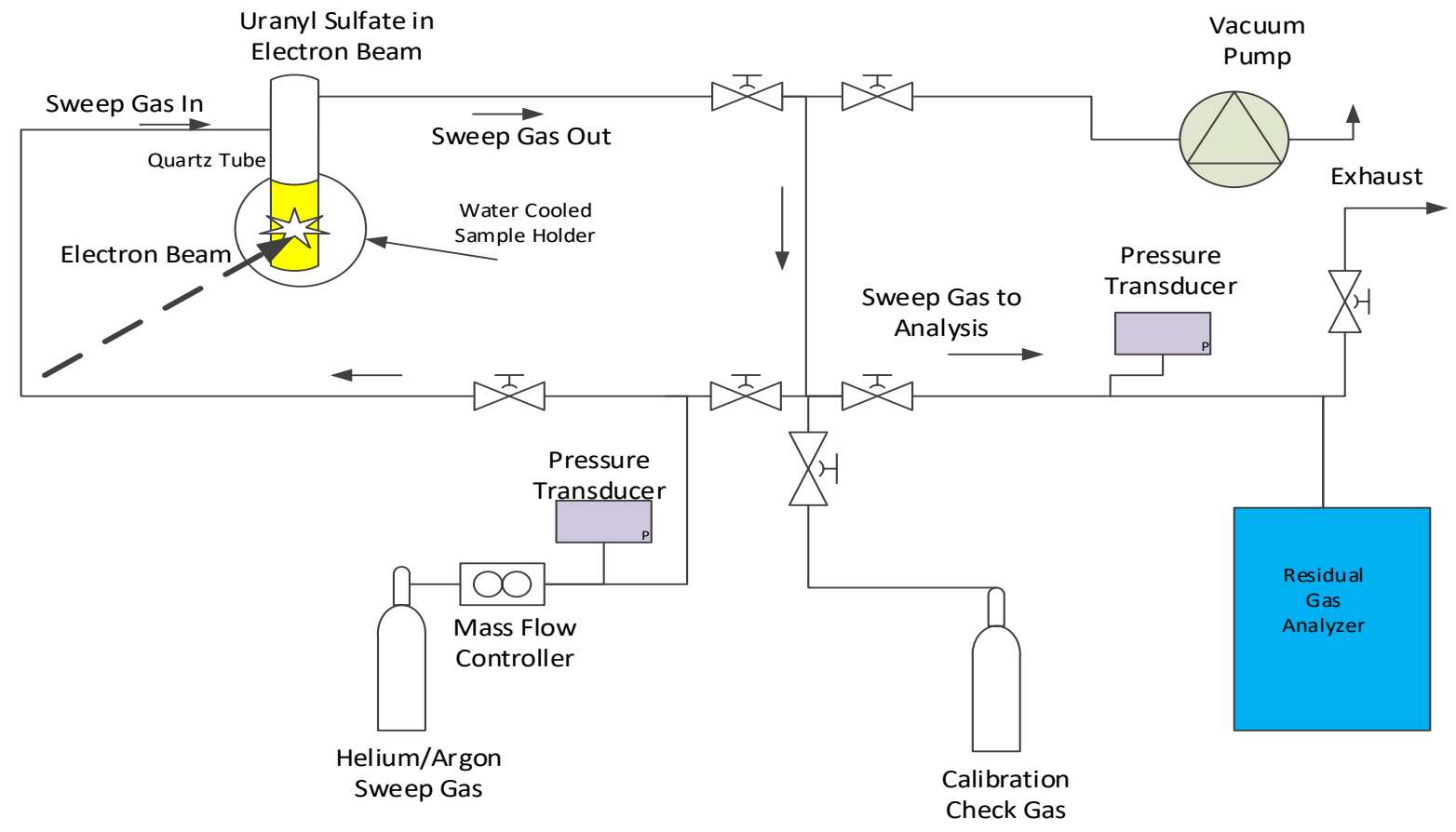

FIGURE 5. Experimental design for the Van de Graaff irradiations.

A quartz tube containing 0.5 to $2 \mathrm{~mL}$ of uranyl-sulfate solution was inserted into a watercooled window located at the end of the Van de Graaff beamline (Figure 6). Connections were made to the set-up, and the system was purged with a He/Ar sweep gas. The chiller was set to the desired temperature, and the $3-\mathrm{MeV}$ electron beam was set to the desired current. The sample was irradiated with the electron beam for a pre-determined length of time. The electron beam impinged on the cooling water and quartz tube. Electrons and X-rays interacted with the uranylsulfate solution, causing radiolysis of water. This generated hydrogen, hydrogen peroxide, and oxygen in the sample vial. The sweep gas flowed in and out of the tube carrying the radiolytic gases, hydrogen and oxygen, to the RGA analytical instrument. The RGA sampled a small portion of the gas, which exited the system through the exhaust. 


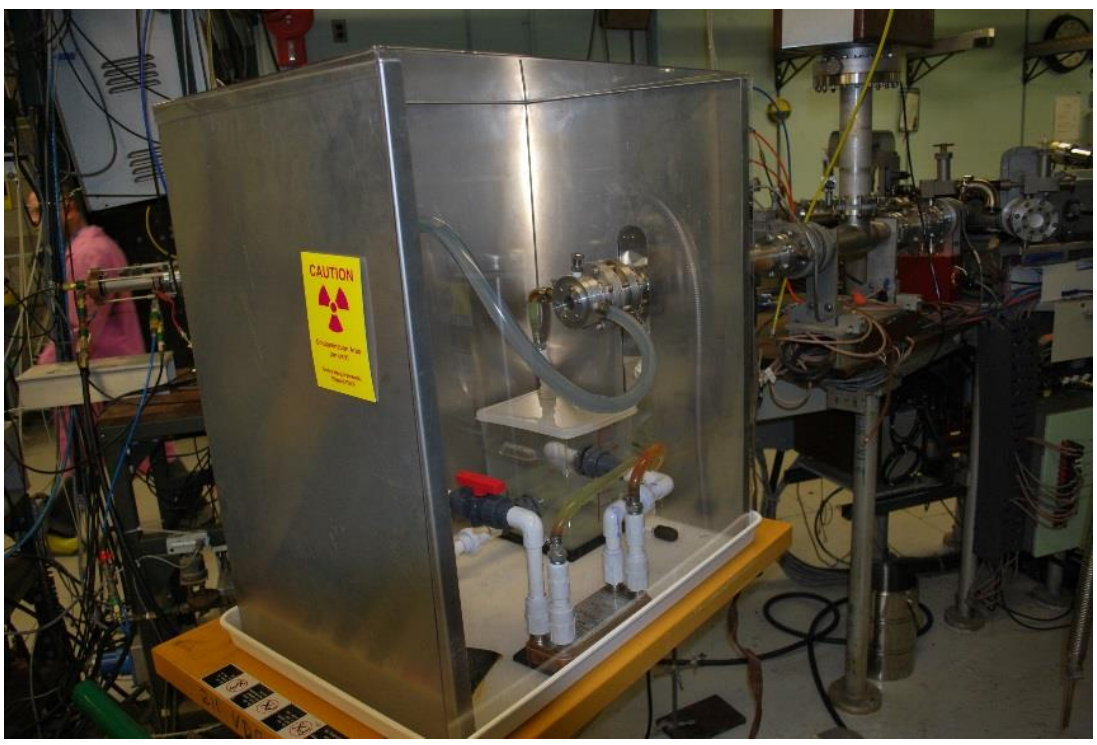

\section{FIGURE 6. Experimental setup for irradiations at the Van de Graaff.}

\subsection{Calculations and Gas Data Analysis}

Gases that were dissolved in solution were not analyzed. The solution was not continuously purged during irradiation to release the dissolved gases. A single-point calibration standard introduced at the sampling pressure was used to calibrate the RGA. Argon at $0.499 \%$ was used as an internal standard. Calibration standards were purchased from the vendor with an uncertainty of $\pm 2 \%$. Calibration checks performed before and after the experiments were within $10 \%$ of the expected value, which equates to an error of $\pm 10 \%$ for the gas results. Equation 10 was used to generate a response factor (RF) for each analyte. It is based on the ion current $\left(\mathrm{IC}_{\text {analyte }}\right)$ and the concentration of the analyte, as well as the ion current $\left(\mathrm{IC}_{\mathrm{is}}\right)$ and concentration ([IS]) of the internal standard:

$$
\mathrm{RF}=\mathrm{IC}_{\text {analyte }} \times[\mathrm{IS}] / \mathrm{IC}_{\mathrm{IS}} \times[\% \text { Analyte }]
$$

The analyte concentration during experiments was determined with Equation 11:

$$
[\% \text { Analyte }]=\mathrm{IC}_{\text {analyte }} \times[\mathrm{IS}] / \mathrm{IC}_{\mathrm{IS}} \times \mathrm{RF}
$$

Calibration by this method made the analysis independent of sample pressure and detector instability. A calibration check was performed prior to each analysis and was reproducible within $\pm 10 \%$ of the true value. Background levels of nitrogen, oxygen, and hydrogen were determined from the blank value and subtracted from the data. During some of the irradiations, a small amount of nitrogen was detected. The source of the nitrogen was most likely outgassing from the stainless steel components of the system, or dissolved gas that liberated from solution during irradiation. As discussed later, Figure 20 shows a close-up of the initial gas generation of three experiments. The data track the outgassing of nitrogen at the onset 
of the experiment. The oxygen values reported were corrected by subtracting a value based on the amount of nitrogen detected related to the ratio of nitrogen to oxygen in air $(0.2683)$ by using Equation 12:

$$
[\% \text { Oxygen Corrected }]=[\% \text { Oxygen }]-[\% \text { Nitrogen }] \times 0.2683
$$

After the concentration of each gas was determined, the total $\mu$ moles of each analyte was calculated from the concentration data. The system was a once-through system with the He/Ar sweep gas flowing at a constant rate set by the mass flow controller. The pressure at the analyzer RGA was kept constant during the experiment. "Room temperature" at the analyzer was constant during the experiments. The RGA sampled the sweep gas as it exited the system. The data generated by the RGA was set by the scan time per atomic mass unit (AMU) of the analyte of interest, so that, as it scanned through the AMUs, it generated a data point for that analyte at a time during the analysis. The relationship between the volume of gas flowing through the system and the analysis time was used to determine the $\mu$ moles of gas generated throughout the experiment and the total generated. The ideal gas law equation was used to find the $\mu$ moles of gas detected, which was summed over the entire experiment for the total by using Equation 13:

$$
\mu \mathrm{m}=[\mathrm{PV} / \mathrm{RT}] \times[\% \text { Analyte } / 100] \times 10^{6}
$$

where $\mu \mathrm{m}=$ micro-moles, $\mathrm{R}=$ gas constant, $\mathrm{T}=$ analysis temperature, $\mathrm{P}=$ analysis pressure, and $\mathrm{V}=$ gas flow $\times$ time interval.

Gas generation data are represented in the tables in units of $\mu \mathrm{mole} / \mathrm{Mrad}$. This is done by dividing the total $\mu$ moles of gas by the total dose (Mrad).

\subsection{Apparent Steady-state Determination}

The time to reach an apparent steady state as listed in the tables is based on observations of gas data when the ratio of hydrogen to oxygen appeared to stabilize within about three-tenths of the total final ratio. This apparent steady state is with respect to gas concentration and is subjective. Only gas data at that time are being considered and should not be thought of as a true steady-state equilibrium, but they may give an indication as to when the solution has achieved some stability with respect to radical diffusion and reactions. They may indicate that the forces driving the solution to one state or another have slowed enough to be observed in the gas data. When precipitation is actively occurring, there could not be a steady state in the solution. In the experiments where delayed precipitation occurred, decreasing temperatures and cessation of radiolysis disrupted that stability. 


\section{RESULTS AND DISCUSSION}

Table 2 shows the makeup of the three different solutions (NU, DU, and LEU) that were irradiated at the Van de Graaff accelerator. The impurity composition was measured by inductively coupled plasma mass spectrometry (ICP-MS) with an error of $\pm 10 \%$. Uranium concentrations were measured by using an inductively coupled optical emission spectrometry (ICP-OES) method developed at NIST for precise determination of element concentrations in solution [8]. When the uranium concentration changed from the values given in Table 2, the concentrations of other metal ions changed proportionately. For our initial experiments, hydrogen peroxide was added to the solutions prior to irradiation because precipitation could not be induced during the last set of irradiations performed in 2014 [3].

TABLE 2. Solutions that were irradiated at the Van de Graff.

\begin{tabular}{ccccccc}
\hline Solution & $\begin{array}{c}\mathrm{Cr} \\
(\mathrm{ppm})\end{array}$ & $\begin{array}{c}\mathrm{Fe} \\
(\mathrm{ppm})\end{array}$ & $\begin{array}{c}\mathrm{Ni} \\
(\mathrm{ppm})\end{array}$ & $\begin{array}{c}\mathrm{Cu} \\
(\mathrm{ppm})\end{array}$ & $\begin{array}{c}\mathrm{Pt} \\
(\mathrm{ppm})\end{array}$ & $\begin{array}{c}\mathrm{NO}_{3}^{-} \\
(\mathrm{mM})\end{array}$ \\
\hline NU - 140 g-U/L & $<0.25$ & $<0.1$ & $<0.05$ & 0.41 & 0.54 & 0 \\
DU - 185 g-U/L & 9.6 & 81 & 6.3 & 4.2 & 0.02 & 500 \\
LEU - 148 g-U/L & 1.1 & 18 & 2.7 & 1.3 & $<0.01$ & 0 \\
\hline
\end{tabular}

Table 3 is a comprehensive description of the conditions and results of a series of experiments where NU and DU solutions were irradiated at the Van de Graaff accelerator. The solution volume, $2 \mathrm{~mL}$, was the same for all samples. The average current (17-20 $\mu \mathrm{A})$ was within $6 \%$ relative standard deviation (RSD) for all samples. The total dose was relatively consistent for all samples except for the 11/21/16 NU sample, which was irradiated for a shorter period of time. The average solution temperatures were within $8 \%$ RSD $\left(61-67^{\circ} \mathrm{C}\right)$ for all samples except the NU sample irradiated on 11/30/16, which had an average solution temperature of $80^{\circ} \mathrm{C}$.

The uranium concentration varied from 90 to $260 \mathrm{~g}-\mathrm{U} / \mathrm{L}$ for the NU and DU samples. It is difficult to determine how the uranium concentration affected the results because conditions were not exactly identical for the samples irradiated with the three different uranium concentrations. The samples with high initial peroxide cannot be compared since the gas data were overall unreliable. For the DU samples, the nitrate in these solutions seemed to have a significant effect on total gas production, showing very low values for $\mathrm{H}_{2}$ and $\mathrm{O}_{2}$ independent of uranium concentration. 


\subsection{NU Samples}

The irradiations on 11/21/16 and 11/22/16 had hydrogen peroxide added at a concentration above the solubility limit of $1 \mathrm{mM}$ with pre-irradiation concentrations of 2.3 and $4.3 \mathrm{mM}$. Dose rates were the same for the two samples, but the sample irradiated on 11/22/16 had a total dose of 13,300 Mrad compared to 10,300 Mrad for the sample irradiated on 11/21/16. A precipitate was observed pre- and post-irradiation in both of these samples; however, the precipitate appeared to be less than what was in solution before irradiation in both samples. Observations from a camera showed the disappearance of the precipitates in both samples as the experiments progressed. The gas generation values for hydrogen and oxygen for these two experiments are suspect because flow from the experiment was higher than what could be measured due to the excessive generation of oxygen. The data are presented for comparison purposes only. The high gas generation values for oxygen observed in the 11/21/16 and 11/22/16 samples as compared to the other samples are indicative of uranyl peroxide decomposition and suggest that uranyl peroxide destruction has occurred. Once a solid has formed, decomposition occurs at a higher rate than formation because significantly more oxygen is observed in the samples, which already had a solid before irradiation.

All other NU samples with the exception of the pre-precipitated samples had $\mathrm{H}_{2}: \mathrm{O}_{2}$ ratios greater than two, and precipitation either did not occur or was observed several days postirradiation. Delayed onset of precipitation occurred in two of the samples (11/29/16 and $12 / 01 / 16$ ), even though the final concentration of free peroxide measured in solution was less than the solubility limit of $1 \mathrm{mM}$ [5]. The hydrogen and oxygen generation values were the lowest for the NU samples that had no hydrogen peroxide added before irradiation.

\subsection{DU Samples}

For the DU samples, gas production rates and measured peroxide concentrations were low due to the $0.5 \mathrm{M}$ nitrate remaining in solution from the method of preparation. Nitrate radiolysis products such as nitrous acid are known to catalyze the destruction of hydrogen peroxide [9]. It took 25-140 minutes to reach an apparent steady state. 
TABLE 3. NU and DU samples irradiated at the Van de Graaff accelerator.

\begin{tabular}{|c|c|c|c|c|c|c|c|c|c|c|c|c|c|c|}
\hline Date & Sample Type & $\begin{array}{c}\text { U-Sulfate } \\
(\mathrm{g}-\mathrm{U} / \mathrm{L})\end{array}$ & $\begin{array}{c}\text { Sample } \\
\text { Size (mL) }\end{array}$ & \begin{tabular}{|c|} 
Sample \\
Temp ( $\left.{ }^{\circ} \mathrm{C}\right)$
\end{tabular} & $\begin{array}{c}\text { Average } \\
\text { Current } \\
(\mu \mathrm{A}) \\
\end{array}$ & $\begin{array}{c}\text { Estimated } \\
\text { Total Dose } \\
\text { (Mrad) } \\
\end{array}$ & $\begin{array}{c}\text { Dose Rate } \\
(\mathrm{Mrad} / \mathrm{min})\end{array}$ & $\begin{array}{l}\text { Measured } \\
\mathrm{H}_{2} \mathrm{O}_{2}(\mu \mathrm{M})\end{array}$ & Precipitation & $\begin{array}{c}\text { Gas Generation } \\
\text { H2 } \\
\text { (umoles/Mrad) }\end{array}$ & $\begin{array}{c}\text { Gas Generation } \\
02 \\
\text { (umoles/Mrad) }\end{array}$ & $\begin{array}{l}\text { Overall } \\
\mathrm{H} \text { to } \mathrm{O} \\
\text { Ratio } \\
\end{array}$ & \begin{tabular}{|} 
Apparent \\
Steady State \\
Time ( min) \\
\end{tabular} & \begin{tabular}{|c} 
Measured \\
H:O Ratio @ \\
Steady State \\
\end{tabular} \\
\hline $12 / 12 / 16$ & $\mathrm{NU}$ & 140 & 2 & 65 & 19 & 13550 & 44 & 130 & NO & 0.045 & 0.019 & 2.4 & 60 & 2.0 \\
\hline $11 / 29 / 16$ & 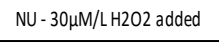 & 140 & 2 & 67 & 20 & 15788 & 47 & 390 & Delayed $^{1}$ & 0.079 & 0.036 & 2.2 & 45 & 2.2 \\
\hline $11 / 30 / 16$ & $\mathrm{NU}$ - $17 \mu \mathrm{M} / \mathrm{L}$ H2O2 added & 140 & 2 & 80 & 20 & 16043 & 48 & 60 & NO & 0.089 & 0.043 & 2.1 & 60 & 2.0 \\
\hline $11 / 17 / 16$ & 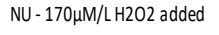 & 140 & 2 & 62 & 18 & 17317 & 42 & 610 & NO & 0.065 & 0.031 & 2.1 & 83 & 2.1 \\
\hline $11 / 21 / 16$ & $\mathrm{NU}-4300 \mu \mathrm{M} / \mathrm{L} \mathrm{H} 2 \mathrm{O} 2$ added & 140 & 2 & 62 & 18 & 10283 & 41 & 540 & YES & 0.075 & 0.049 & 1.5 & 140 & 2.1 \\
\hline $11 / 22 / 16$ & $\mathrm{NU}-2300 \mu \mathrm{M} / \mathrm{L}$ H2O2 added & 260 & 2 & 61 & 17 & 13329 & 41 & 60 & YES & 0.122 & 0.087 & 1.4 & 140 & 2.0 \\
\hline 12/01/16 & 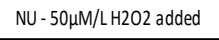 & 90 & 2 & 66 & 20 & 15820 & 46 & 800 & Delayed $^{2}$ & 0.101 & 0.046 & 2.2 & 42 & 2.1 \\
\hline $12 / 08 / 16$ & 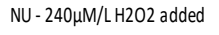 & 90 & 2 & 67 & 20 & 15015 & 47 & 840 & NO & 0.104 & 0.047 & 2.2 & 50 & 2.1 \\
\hline $12 / 13 / 16$ & $\mathrm{NU}$ - $130 \mu \mathrm{M} / \mathrm{L}$ H2O2 added & 90 & 2 & 62 & 18 & 15085 & 41 & 880 & NO & 0.100 & 0.043 & 2.4 & 130 & 2.2 \\
\hline $12 / 06 / 16$ & DU - 50رM/L H2O2 added & 140 & 2 & 66 & 19 & 12179 & 48 & 100 & NO & 0.011 & 0.005 & 2.2 & 25 & 2.2 \\
\hline $12 / 07 / 16$ & DU - 55 $\mu \mathrm{M} / \mathrm{L}$ H2O2 added & 90 & 2 & 66 & 20 & 14892 & 46 & 6 & NO & 0.011 & 0.005 & 2.5 & 30 & 2.5 \\
\hline
\end{tabular}

1 Sample was cloudy on 12/07/16, and precipitate was observed on 12/22/16.

2 Precipitate was observed on 12/06/16. Gas data for samples irradiated on 11/21/16 and 11/22/16 were only estimated due to the high flow caused by the large amount of oxygen produced.

Figures 7 through 11 show the gas generation data for samples irradiated on 12/12/16, 11/17/16, 11/29/16, 11/21/16, and 12/6/16. All graphs are presented together for comparison. Figure 7 (NU 12/12/16) is for the sample irradiated without any additional hydrogen peroxide before irradiation. The experiment for Figure 8 (NU 11/17/16) had a low initial hydrogen peroxide concentration added, and no precipitation occurred. The experiment for Figure 9 (NU 11/29/16) had a low initial peroxide concentration, and delayed precipitation occurred. The experiment for Figure 10 (NU 11/21/16) had a high initial peroxide concentration, and a precipitate was present from the start of the experiment. The experiment for Figure 11 (DU 12/6/16) had nitrate and a low initial hydrogen peroxide concentration added, and precipitation did not occur. Each figure shows the mole\% of the oxygen, hydrogen, nitrogen (interfering species), and argon (internal standard) on the primary y-axis, and the total dose (Mrad) on the secondary $y$-axis as a function of time.

For all figures, most of the undulations in hydrogen and oxygen concentration that occurred during an experiment may be explained by the beam power fluctuations that occurred during irradiation. Beam current measurements were taken at approximately 20-minute intervals. Initial measurements show beam power at $20 \mu \mathrm{A}$, but 20 minutes later it typically varied by $\pm 1 \mu \mathrm{A}$. Depending on the beam stability, it could vary by as much as $\pm 5 \mu \mathrm{A}$. Also, when the measurement is taken, a three-second pause where the beam is temporarily interrupted occurs. Arcs, which sometimes occur, cause a temporary increase in beam current. Not all artifacts in the gas generation graphs can be attributed to beam instability, however. Figures 7 and 8 are examples where erratic behavior in gas generation occurred. Especially in Figure 8a, there were two increases in gas production. The increase in gas generation is also apparent in Figure 8b, which shows total $\mu$ moles of gas and current over time. At about 130 minutes the rate of both hydrogen and oxygen increased significantly. This caused the experimenter to turn up the flow of purge gas to reduce the hydrogen concentration in the sample tube. Part of the safety basis required to perform the experiment was to keep the hydrogen concentration at or below $2 \%$. This 
is why the extremely sharp increase smooths out. However, it is not clear what caused this behavior.

In Figures 7-9 and 11, hydrogen is generated first from the solution, followed by oxygen. However, in the experiment for Figure 10, which had a high initial hydrogen peroxide concentration and uranyl peroxide present before irradiation, oxygen was generated at a significant rate. The high initial oxygen production is due to radiolysis of uranyl peroxide. Hydrogen is generated at a similar rate to the other experiments. Figure 11 also shows slightly faster oxygen generation compared to Figures 7-9 but not as dramatically as seen in Figure 10. This is due to the presence of nitrate in the solution. It is known that the nitrogen oxides and radicals facilitate the decomposition of hydrogen peroxide. This finding may indicate that the formation of oxygen in these experiments is mostly due to the decomposition of peroxides. Figure 11 shows the lowest overall gas generation for both hydrogen and oxygen, indicating that the presence of nitrate plays a significant role in the DU solutions containing nitrate.

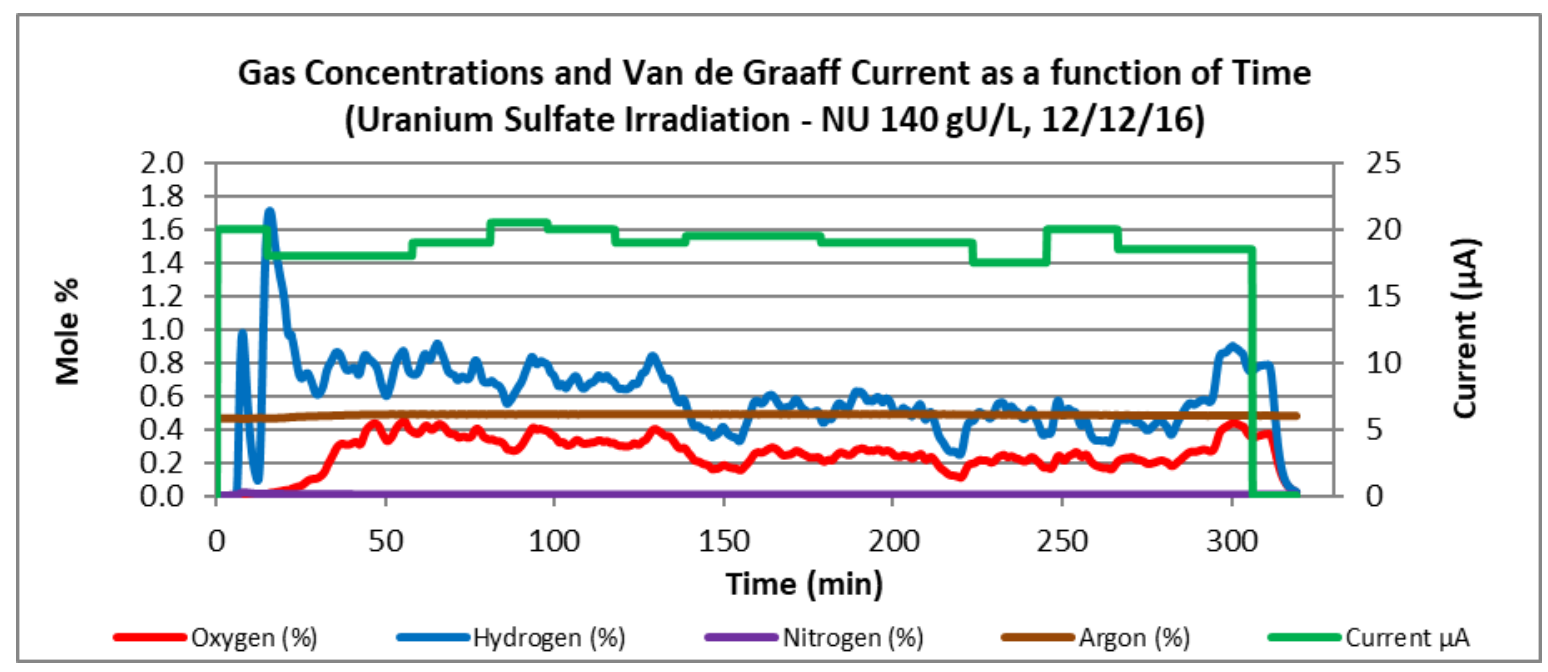

FIGURE 7. Gas generation and Van de Graaff current as a function of time for NU sample irradiated without additional hydrogen peroxide before irradiation $(12 / 12 / 16)$. 


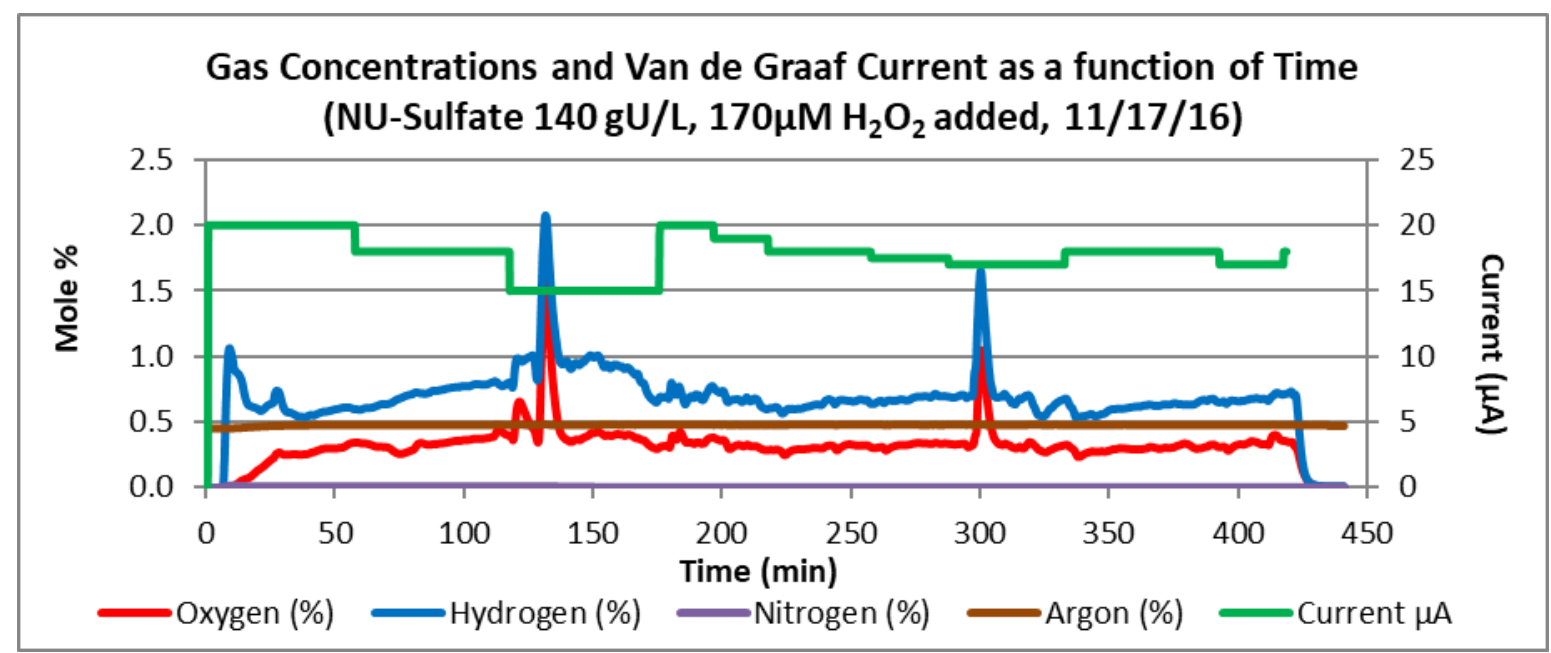

FIGURE 8a. Gas generation and Van de Graaff current as a function of time for NU experiment (11/17/16), which had a low initial hydrogen peroxide concentration added and no precipitation.

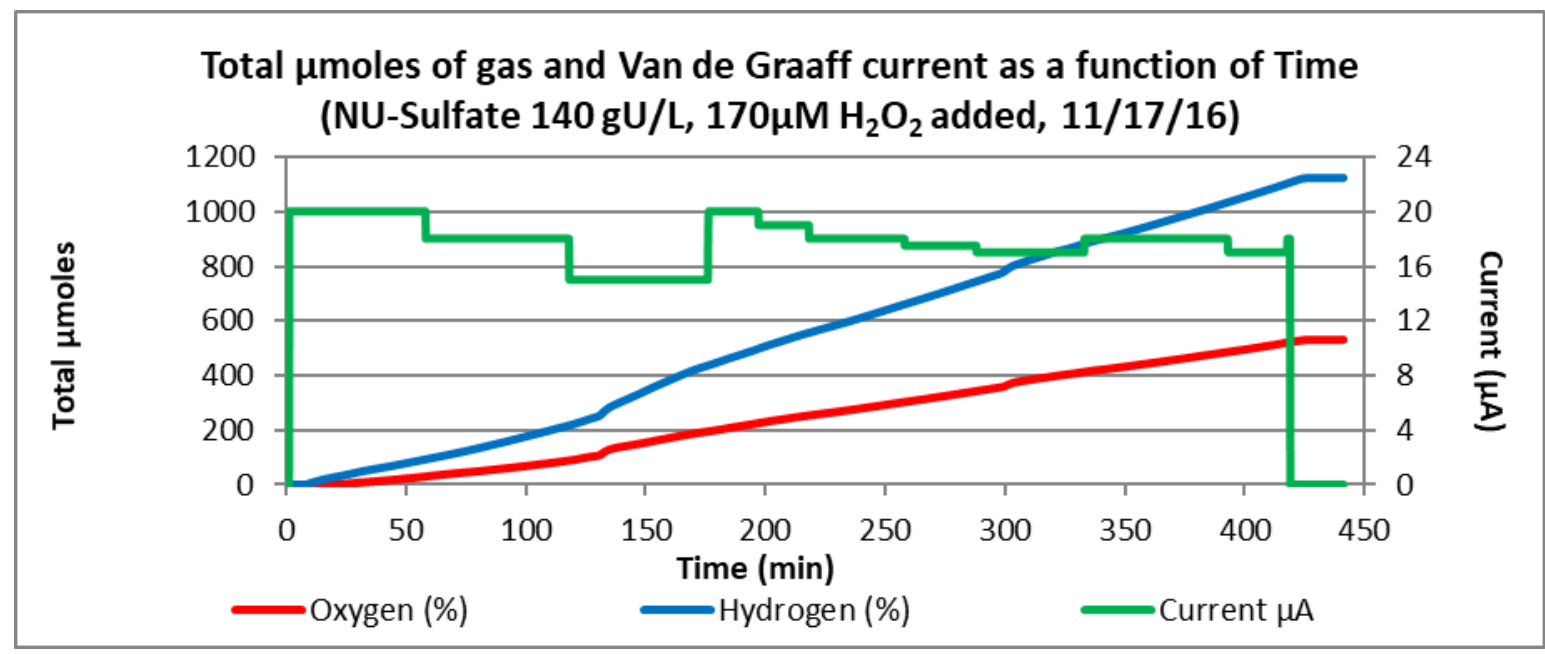

FIGURE 8b. Total $\mu$ moles of gas and Van de Graaff current as a function of time for NU experiment (11/17/16), which had a low initial hydrogen peroxide concentration added and no precipitation. 


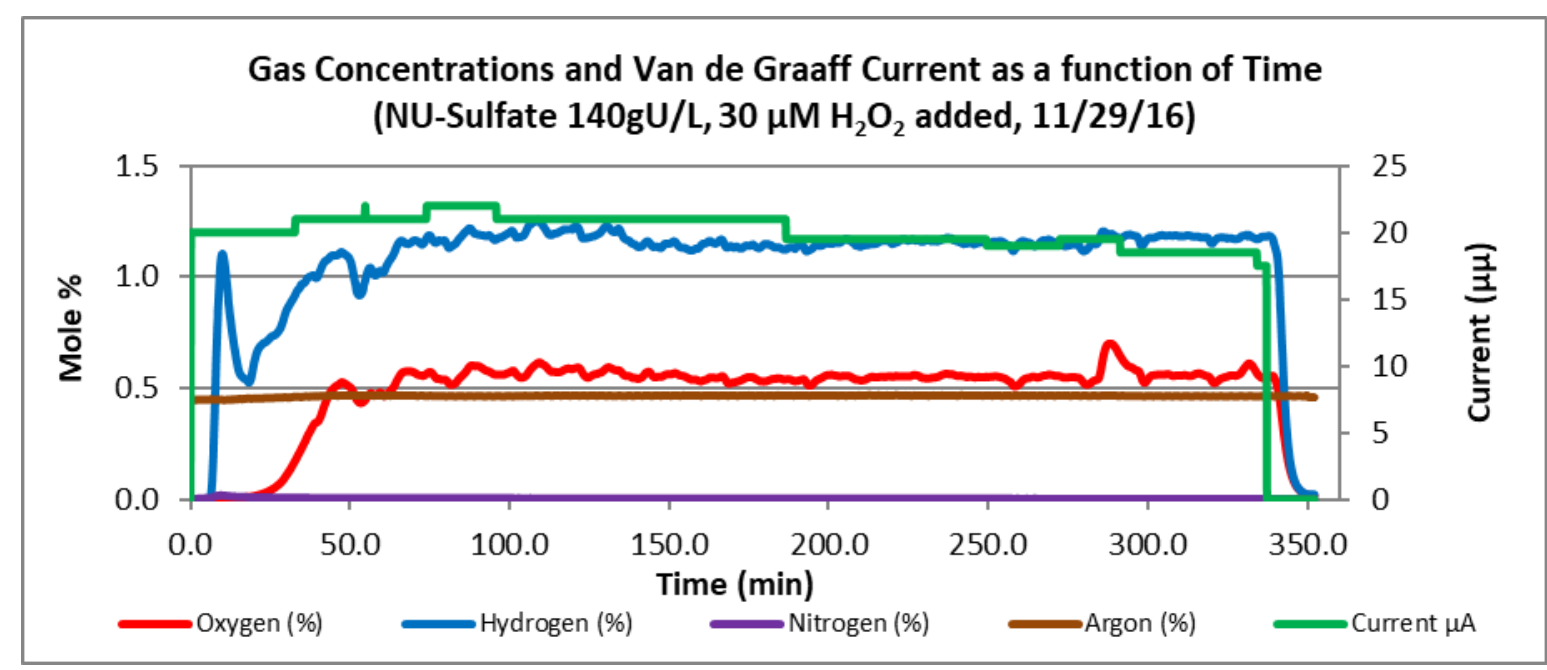

FIGURE 9. Gas generation and Van de Graaff current as a function of time for NU experiment (11/29/16), which had a low initial peroxide concentration and delayed precipitation.

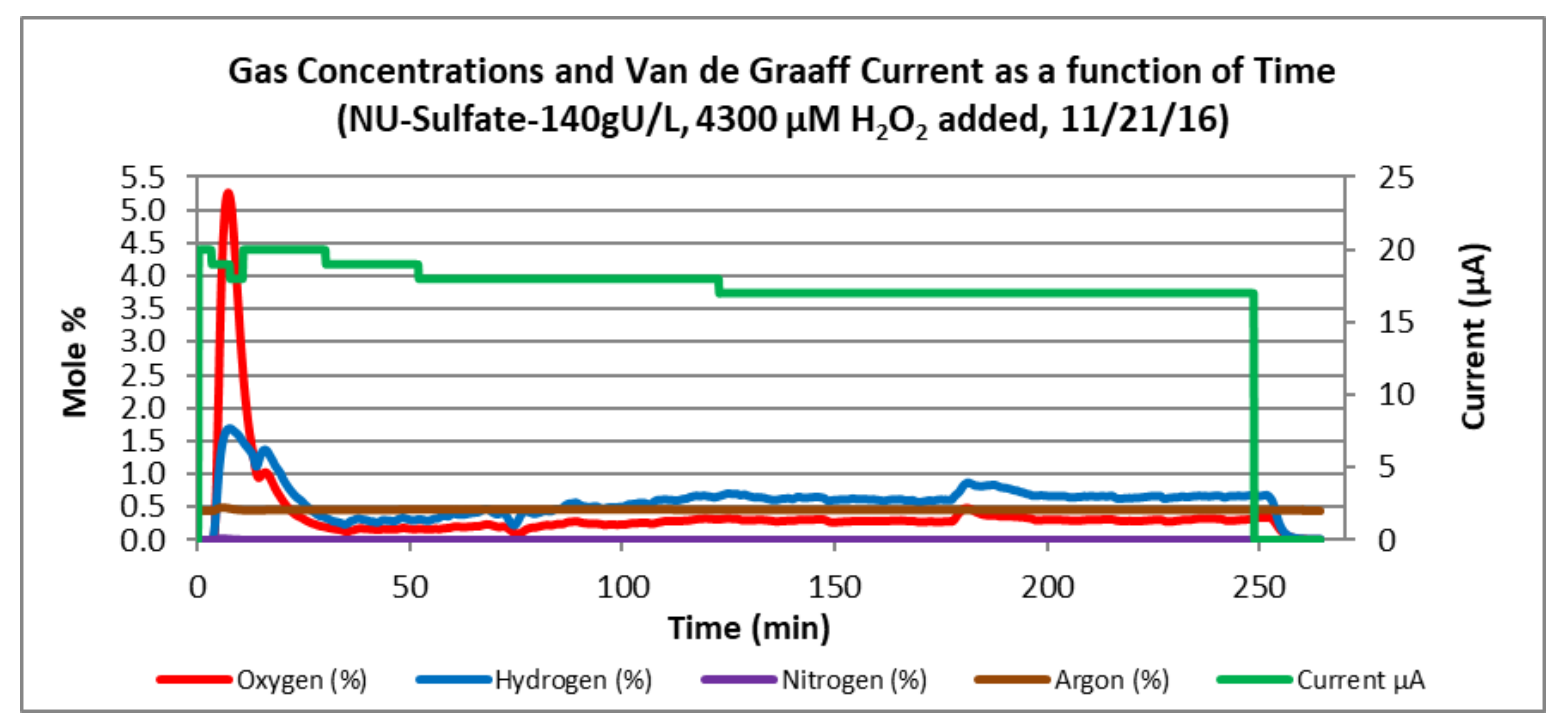

FIGURE 10. Gas generation and Van de Graaff current as a function of time for NU experiment (11/21/16), which had a high initial peroxide concentration and precipitate present from the start. 


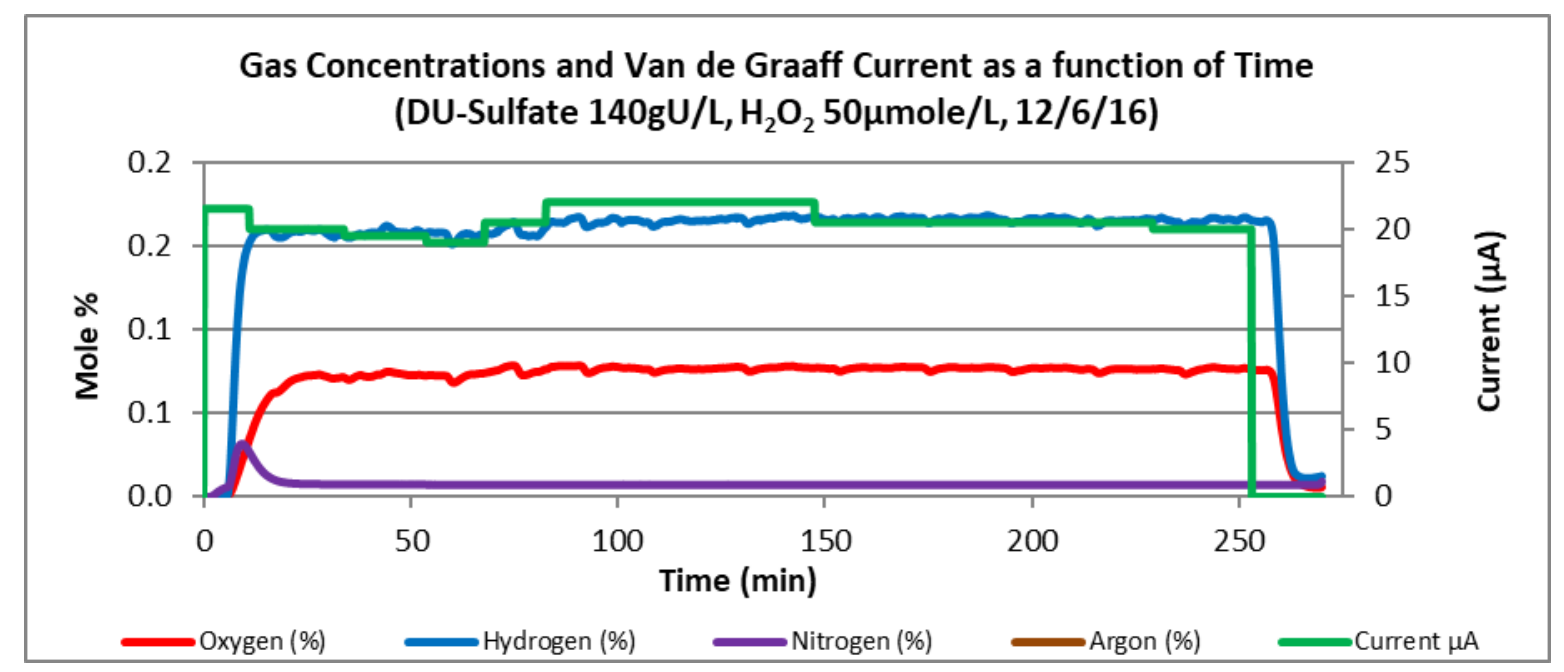

FIGURE 11. Gas generation and Van de Graaff current as a function of time for DU experiment (12/6/16), which had nitrate and a low initial hydrogen peroxide concentration added and no precipitation.

\subsection{LEU Samples}

Table 4 shows the LEU solutions irradiated at the Van de Graaff accelerator; the table also includes results for irradiation of $\mathrm{pH} 1$ sulfuric acid (3/9/17) for comparison. The solution volume was the same $(2 \mathrm{~mL})$ for all samples. The uranium concentration was approximately the same for all samples shown in Table 4. The LEU samples (12/15/16 and 12/20/16) irradiated without an additional catalyst before irradiation had a $5 \%$ higher concentration, which was due to the slight dilution from the addition of a catalyst to all other samples. The LEU solutions irradiated on 12/15/16 and 12/20/16 did not contain an additional catalyst and were irradiated under similar conditions. They are replicates of each other and serve as the base to compare to the LEU samples irradiated with catalysts. The remaining LEU samples in Table 4 had various catalysts added prior to irradiation to prevent the precipitation of uranyl peroxide. Tests were performed with different catalyst concentrations to determine the lowest amount required to prevent precipitation. The effect of different dose rates was examined as well, which was determined by changing the current of the accelerator.

All catalysts were effective at catalyzing the destruction of peroxide to the extent of preventing precipitation, except for the sample irradiated on $03 / 09 / 17$, where $500 \mathrm{ppm}$ of $\mathrm{Cu}^{2+}$ was added as $\mathrm{CuSO}_{4}$ to the solution. Because the metal ions present in solution (such as $\mathrm{Fe}^{2+}$, $\mathrm{Fe}^{3+}$, or $\mathrm{Cu}^{2+}$ ) interfered with the spectrophotometric method used to measure peroxide concentration, $\mathrm{NaF}$ was added to the solution prior to the peroxide measurements to complex the metal ions and prevent interference in samples where a catalyst was added, as shown in Table 4 [5]. 
TABLE 4. Results for LEU samples irradiated at the Van de Graaff accelerator (from 12/15/16 to $3 / 22 / 17$ ).

\begin{tabular}{|c|c|c|c|c|c|c|c|c|c|c|c|c|c|c|c|}
\hline Date & Sample Type & $\begin{array}{c}\text { U.Sulfate } \\
(\mathrm{g}-U / L)\end{array}$ & $\begin{array}{l}\text { Sample } \\
\text { Size (mL) }\end{array}$ & \begin{tabular}{|c|} 
Sample \\
Temp $\left({ }^{\circ}\right)$
\end{tabular} & \begin{tabular}{|l|} 
Irradiation \\
Time (min)
\end{tabular} & \begin{tabular}{|c|}
$\begin{array}{c}\text { Average } \\
\text { Current } \\
(\mu \mathrm{A})\end{array}$ \\
\end{tabular} & \begin{tabular}{|c} 
Estimated \\
Total Dose \\
(Mrad) \\
\end{tabular} & $\begin{array}{c}\text { Dose Rate } \\
\text { (Mrad/min) }\end{array}$ & $\begin{array}{c}\text { Measured } \mathrm{H}_{2} \mathrm{O}_{2} \\
(\mu \mathrm{M})\end{array}$ & Precipitation & $\begin{array}{c}\mathrm{H}_{2} \\
\text { (umoles/Mrad) }\end{array}$ & $\begin{array}{c}\mathrm{O}_{2} \\
\text { (umoles/Mrad) }\end{array}$ & $\begin{array}{c}\text { Overall } \\
\text { Hto } 0 \\
\text { Ratio } \\
\end{array}$ & \begin{tabular}{|c|} 
Apparent \\
Steady State \\
Time (min) \\
\end{tabular} & $\begin{array}{c}\text { Measured H:O } \\
\text { Ratio @ } \\
\text { Steady State }\end{array}$ \\
\hline 12/15/16 & LEU & 148 & 2 & 67 & 360 & 20 & 16,728 & 46 & 100 & YES & 0.135 & 0.054 & 2.5 & 60 & 2.3 \\
\hline $12 / 20 / 16$ & LEU & 148 & 2 & 64 & 329 & 19 & 13,990 & 43 & 17 & YES & 0.146 & 0.060 & 2.4 & 60 & 2.3 \\
\hline $03 / 02 / 17$ & LEU - Fe $\mathrm{Fe}^{+2} @ 1000 \mathrm{ppm}$ & 140 & 2 & 70 & 360 & 21 & 17,994 & 50 & $1300^{*}$ & NO & 0.025 & 0.010 & 2.4 & 55 & 2.4 \\
\hline 03/06/17 & LEU - Fe $\mathrm{e}^{+2} @ 1000 \mathrm{ppm}$ & 140 & 2 & 31 & 360 & 5 & 4,150 & 12 & $2100^{*}$ & NO & 0.011 & 0.002 & 5.4 & 252 & 3.1 \\
\hline 03/08/17 & LEU - Fe $\mathrm{Fe}^{+2} @ 500 \mathrm{ppm}$ & 140 & 2 & 71 & 366 & 22 & 18,519 & 51 & $16^{*}$ & NO & 0.039 & 0.017 & 2.3 & 50 & 2.3 \\
\hline 03/07/17 & LEU - Fe ${ }^{+2} @ 500 p p m$ & 140 & 2 & 29 & 360 & 4 & 3,295 & 9 & $440^{*}$ & NO & 0.057 & 0.023 & 2.5 & 107 & 2.3 \\
\hline $03 / 16 / 17$ & LEU - Fe ${ }^{+2} @ 200 p p m$ & 140 & 2 & 30 & 360 & 4 & 3,575 & 10 & $2600^{*}$ & NO & 0.048 & 0.019 & 2.5 & 173 & 2.4 \\
\hline 03/09/17 & LEU - Cu ${ }^{+2} @ 500 \mathrm{ppm}$ & 140 & 2 & 32 & 366 & 5 & 4,541 & 12 & $1600^{*}$ & YES & 0.066 & 0.027 & 2.5 & $N / A$ & $\mathrm{~N} / \mathrm{A}$ \\
\hline $03 / 22 / 17$ & LEU $-\mathrm{Fe}^{+2} \& \mathrm{Cu}^{+2} @ 100 \mathrm{ppm}$ & 140 & 2 & 28 & 120 & 4 & 1,112 & 9 & $860^{*}$ & NO & 0.032 & 0.011 & 2.7 & $\mathrm{~N} / \mathrm{A}$ & $N / A$ \\
\hline $03 / 22 / 17$ & LEU - Fe ${ }^{+3} @ 250 \mathrm{ppm}$ & 140 & 2 & 40 & 120 & 4 & 1,336 & 11 & $1600^{*}$ & No & 0.030 & 0.009 & 3.2 & $\mathrm{~N} / \mathrm{A}$ & $N / A$ \\
\hline 03/09/17 & pH-1 Sulfuric Acid & $N / A$ & 2 & 66 & 331 & 20 & 15,146 & 46 & 1400 & NO & 0.018 & 0.008 & 2.3 & 60 & 2.4 \\
\hline
\end{tabular}

* $\mathrm{NaF}$ was added as a complexant.

Samples irradiated on 12/15/16 and 12/20/16 showed signs of precipitation within 20 minutes of irradiation based on camera images during irradiation. The differences in temperature and dose rate are due to the slight difference in the average current. The measured $\mathrm{H}_{2} \mathrm{O}_{2}$ concentration for both samples was less than the solubility limit of $1 \mathrm{mM}$. This low solubility is due to free peroxide reacting to form the precipitate, which leaves little free peroxide left in solution. The ratio of hydrogen to oxygen is $>2$, which is not surprising based on Equation 1, where the precipitation of uranyl peroxide causes oxygen atoms to bind, leaving two atoms of hydrogen as acid in solution.

Samples irradiated on 3/2/17 and 3/6/17 both had 1000 ppm Fe ${ }^{2+}$, which was effective at preventing uranyl peroxide precipitation. When compared to the unadulterated samples, the major difference was lower gas generation for hydrogen and oxygen in the samples with $1000 \mathrm{ppm} \mathrm{Fe}{ }^{2+}$. The other factor being tested was the effect of dose rate. The 3/6/17 sample was run at a lower dose rate $(12 \mathrm{vs} .50 \mathrm{Mrad} / \mathrm{min})$. The dose rate differences affected the amount of time it took to reach an apparent steady state and the generation of $\mathrm{H}_{2}$ and $\mathrm{O}_{2}$. Generation values were lower at a lower dose rate, and the time it took to reach an apparent steady state was longer at a lower dose rate.

Experiments performed on $3 / 8 / 17,3 / 7 / 17$, and 3/16/17 were run to test a lower concentration of $\mathrm{Fe}^{2+}$ and to see if it was effective at preventing precipitation at a lower temperature. The addition of $200 \mathrm{ppm} \mathrm{Fe}^{2+}$ was effective at preventing precipitation of uranyl peroxide, even at a temperature of $19^{\circ} \mathrm{C}$. The dose rate was lower for this sample, but it had earlier been shown that precipitation will occur at the lower dose rate without a catalyst. (See data for the 2/6/17 LEU experiment in Table 6.) 
In the samples that had a low final free peroxide concentration, a significant amount of precipitate had formed during irradiation, reducing the amount of free peroxide available for the measurements. The overall hydrogen-to-oxygen ratios were higher than 2 for all of the LEU samples irradiated without the addition of a catalyst.

The next eight LEU samples shown in Table 4 were irradiated with a metal catalyst such as $\mathrm{FeSO}_{4}, \mathrm{CuSO}_{4}$, or $\mathrm{Fe}_{2}\left(\mathrm{SO}_{4}\right)_{3}$. The addition of $500 \mathrm{ppm} \mathrm{Cu}^{2+}$ was not effective at preventing precipitation. At least $200 \mathrm{ppm} \mathrm{Fe}{ }^{2+}$ or $250 \mathrm{ppm} \mathrm{Fe}^{3+}$ was required to prevent precipitation or a combination of $100 \mathrm{ppm} \mathrm{Fe}^{2+}$ as $\mathrm{FeSO}_{4}$ and $100 \mathrm{ppm} \mathrm{Cu}^{2+}$ as $\mathrm{CuSO}_{4}$. All samples irradiated showed hydrogen-to-oxygen ratios greater than 2 , and the sample irradiated with $250 \mathrm{ppm} \mathrm{Fe}$ as $\mathrm{Fe}_{3}\left(\mathrm{SO}_{4}\right)_{2}$ had a final $\mathrm{H}_{2}: \mathrm{O}_{2}$ ratio of 3 .

The time for all Table 4 samples to reach a steady state was approximately 50-250 minutes, Except for both samples irradiated on 03/22/17, which were not irradiated long enough for an apparent steady state to be reached. The catalysts tested except for $500 \mathrm{ppm} \mathrm{Cu}{ }^{2+}$ increased the destruction of peroxide at a rate fast enough to prevent accumulation of peroxide to cause precipitation. Total gas production represented by generation values showed a trend when $\mathrm{Fe}^{2+}$ peroxide catalyst is added to the uranium solution, namely, $\mathrm{Fe}^{2+}$ causes a significant decrease in hydrogen and oxygen generation. One explanation may be that $\mathrm{Fe}^{3+}$ is acting as an electron scavenger. In the reactions with iron salts and hydrogen peroxide, $\mathrm{Fe}^{2+}$ is oxidized to $\mathrm{Fe}^{3+}$ by peroxide to form the $\mathrm{OH}$ radical (equations 14-17) [10]:

$$
\begin{aligned}
& \mathrm{Fe}^{2+}+\mathrm{H}_{2} \mathrm{O}_{2} \rightarrow \mathrm{Fe}^{3+}+\mathrm{OH}^{-}+\mathrm{OH} \bullet \\
& \mathrm{H}_{2} \mathrm{O}_{2}+\mathrm{OH} \bullet \rightarrow \mathrm{HO}_{2} \bullet+\mathrm{H}_{2} \mathrm{O} \\
& \mathrm{HO}_{2} \bullet+\mathrm{H}_{2} \mathrm{O}_{2} \rightarrow \mathrm{O}_{2}+\mathrm{H}_{2} \mathrm{O}+\mathrm{OH} \bullet \\
& \mathrm{Fe}^{2+}+\mathrm{OH} \bullet \rightarrow \mathrm{Fe}^{3+}+\mathrm{OH}^{-}
\end{aligned}
$$

The radical goes on to decompose hydrogen peroxide. It also becomes the chain breaker by oxidizing $\mathrm{Fe}^{2+}$ to $\mathrm{Fe}^{3+}$. Although $\mathrm{Fe}^{3+}$ can participate in the decomposition of hydrogen peroxide (equations 18-20) [11], literature suggests that the reaction is highly $\mathrm{pH}$ dependent [12].

$$
\begin{aligned}
& \mathrm{Fe}^{3+}+\mathrm{HO}_{2} \bullet \rightarrow \mathrm{Fe}^{2+}+\mathrm{H}^{+}+\mathrm{O}_{2} \\
& \mathrm{Fe}^{3+}+\mathrm{H}_{2} \mathrm{O}_{2} \rightarrow \mathrm{Fe}^{2+}+\mathrm{H}^{+}+\mathrm{HO}_{2} \bullet \\
& \mathrm{Fe}^{2+}+\mathrm{HO}_{2} \bullet+\mathrm{H}^{+} \rightarrow \mathrm{Fe}^{3+}+\mathrm{H}_{2} \mathrm{O}_{2}
\end{aligned}
$$

The products of radiolysis are $\mathrm{H}_{2} \mathrm{O} \bullet, \mathrm{OH}^{\bullet}, \mathrm{OH}^{-}, \mathrm{H}_{2} \mathrm{O}_{2}, \mathrm{H}_{2}, \mathrm{H}^{+}$, and $\mathrm{e}_{(\text {aq) }}^{-}$, where the aqueous electron is due to the ionization of water (equation 20) [1]. The electron can facilitate the formation of the molecular products hydrogen, peroxide, and ultimately oxygen from peroxide decomposition: 


$$
\begin{aligned}
& \mathrm{H}_{2} \mathrm{O} \rightarrow \mathrm{H}_{2} \mathrm{O}^{+}+\mathrm{e}^{-} \\
& \mathrm{H}_{2} \mathrm{O}^{+}+\mathrm{H}_{2} \mathrm{O} \rightarrow \mathrm{OH}^{-}+\mathrm{H}_{3} \mathrm{O}^{+} \\
& \mathrm{e}^{-}+\mathrm{H}_{2} \mathrm{O} \rightarrow{ }^{-} \mathrm{H}+\mathrm{OH}^{-} \\
& -\mathrm{H}+\mathrm{H}_{2} \mathrm{O} \rightarrow \mathrm{H}_{2}+\mathrm{OH}^{-} \\
& \mathrm{OH}^{-}+\mathrm{H}_{2} \mathrm{O} \rightarrow \mathrm{H}_{2} \mathrm{O}_{2}+\mathrm{H}^{-} \\
& \mathrm{OH}^{-}+\mathrm{HO}_{2}^{-} \rightarrow \mathrm{H}_{2} \mathrm{O}+\mathrm{O}_{2}
\end{aligned}
$$

If $\mathrm{Fe}^{3+}$ scavenges the aqueous electron, this process should quench its reaction pathway, thus decreasing the total gas production. Also, this process may act to keep an active source of $\mathrm{Fe}^{2+}$ in solution for the decomposition of peroxide. This is only one possible explanation, and additional work on this topic would be beneficial.

Figures 12 through 14 show gas analysis data associated with the Table 4 samples irradiated on $12 / 20 / 16,3 / 16 / 17$, and $3 / 9 / 17$. These figures show representative gas generation behavior for an LEU sample where no catalyst was added and for some samples with catalyst additions. The figures show gas-generation data and Van de Graaff current as a function of time.

Figure 12 shows the LEU sample where uranyl peroxide precipitated during irradiation. Hydrogen was evolved from solution first followed by oxygen. $\mathrm{The}_{2} \mathrm{H}_{2}-\mathrm{to}-\mathrm{O}_{2}$ ratio is 2.4 due to the consumption of oxygen through the precipitation of uranyl peroxide.

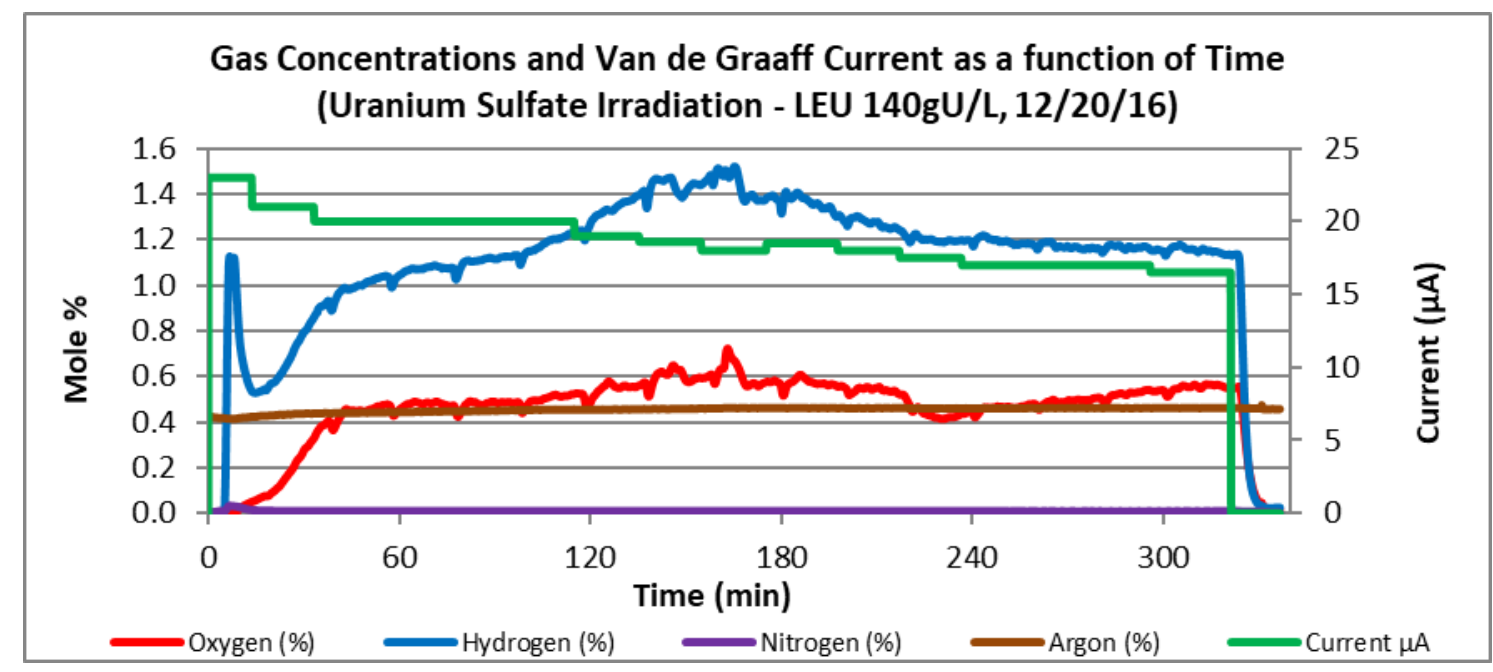

FIGURE 12. Gas generation and Van de Graaff current as a function of time for sample irradiated on 12/20/16. 
Figure 13 shows the generation of gases as a function of total dose for the LEU sample where $500 \mathrm{ppm} \mathrm{Cu}^{2+}$ was added as $\mathrm{CuSO}_{4}$ to the solution before irradiation, but a precipitate still formed. The $\mathrm{H}_{2}: \mathrm{O}_{2}$ ratio ended at 2.5 for this irradiation. It was very high during the beginning of the irradiation due to $\mathrm{O}_{2}$ being consumed as peroxide.

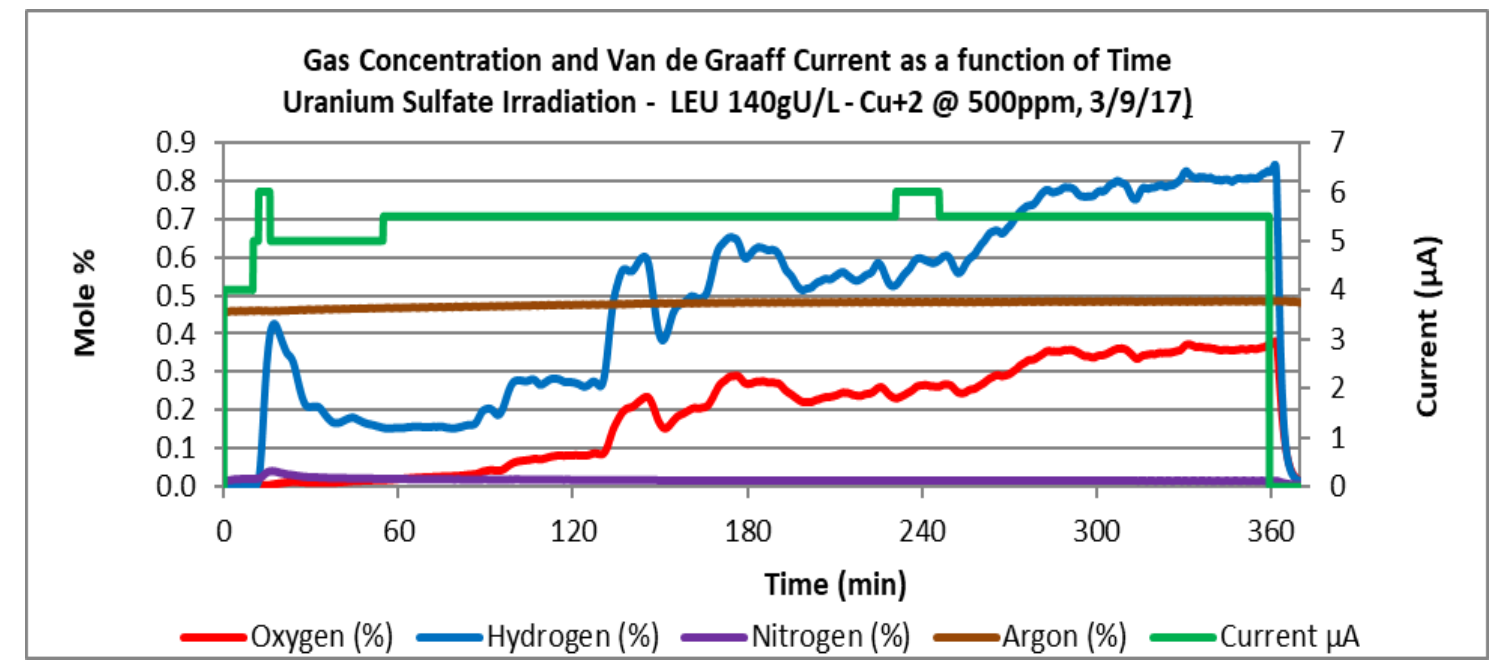

FIGURE 13. Gas generation and Van de Graaff current as a function of time for sample irradiated on 3/9/17.

Figure 14 shows typical gas behavior for a sample irradiated with a catalyst $\left(500 \mathrm{ppm} \mathrm{Fe}^{2+}\right)$ that was effective at preventing uranyl peroxide precipitation during and after irradiation. The $\mathrm{H}_{2}: \mathrm{O}_{2}$ ratio ended at 2.5 for this irradiation. It was very high during the beginning of the irradiation due to $\mathrm{O}_{2}$ being consumed as peroxide. During the second half of the irradiation, the ratio declined to closer to two. Another aspect is the relative stability of gas generation compared to Figures 12 and 13. 


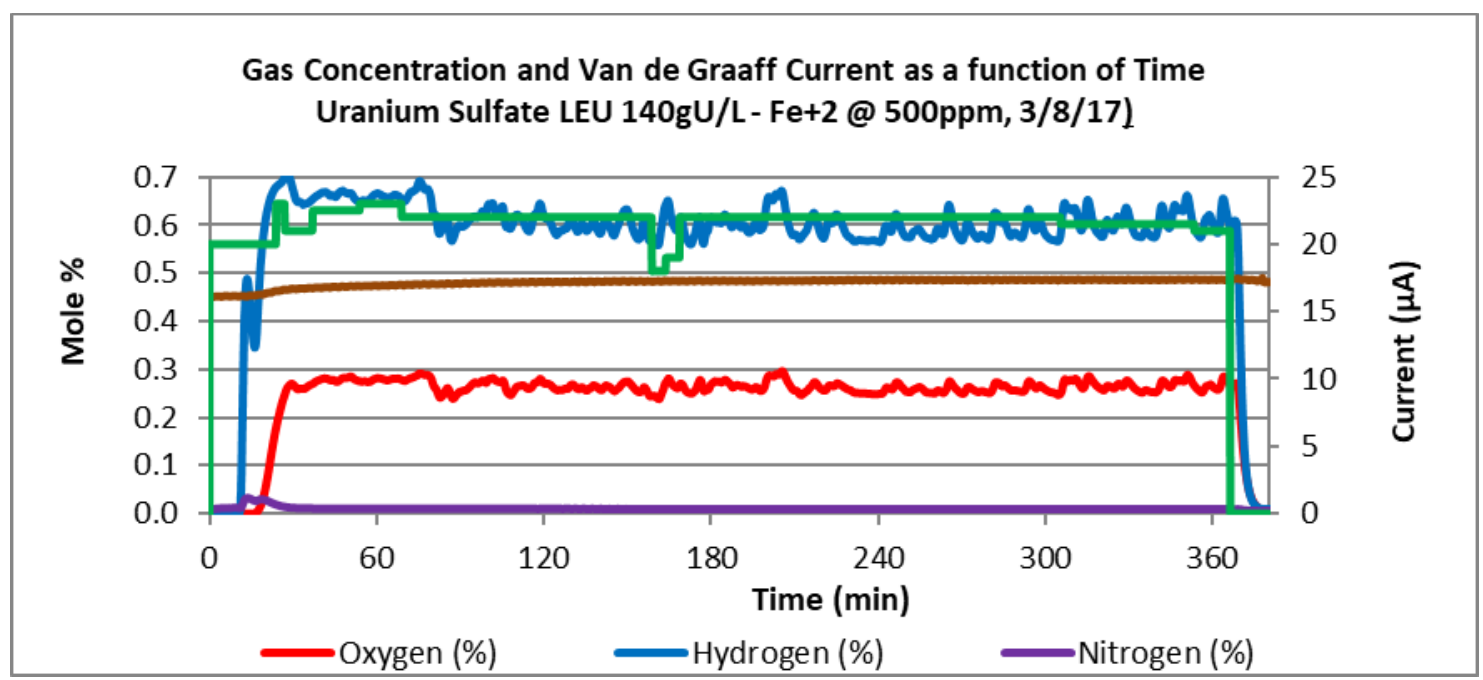

\section{FIGURE 14. Gas generation and Van de Graaff current as a function of time for sample irradiated on $3 / 8 / 17$.}

Table 5 shows results for LEU solutions that were irradiated at the Van de Graaff accelerator at $5 \mu \mathrm{A}$ current, an average solution temperature of $34^{\circ} \mathrm{C}$, and a solution volume of $0.5 \mathrm{~mL}$. Irradiation times varied from 254 to 365 minutes, and the average dose rate was $40 \mathrm{Mrad} / \mathrm{min}$. The addition of a Pt wire, stainless steel mesh, $8 \mu \mathrm{M} \mathrm{KI}$, and $100 \mathrm{ppm} \mathrm{Fe}{ }^{2+}$ as $\mathrm{FeSO}_{4}$ was not effective at catalyzing the destruction of peroxide to the extent of preventing precipitation.

The measured peroxide concentration post-irradiation in all of the samples was above the solubility limit of $1 \mathrm{mM}$ [3], but the value for samples irradiated with $100 \mathrm{ppm} \mathrm{Fe}{ }^{2+}$ were artificially high because a complexant was not added to minimize interference from $\mathrm{Fe}^{2+}$. In all of these samples, precipitation occurred during irradiation, and the results with stainless steel mesh disagree with previous results obtained in 2012, where stainless steel mesh prevented precipitation [2]. Temperature most likely played a role in the different results obtained with stainless steel mesh in 2012 and 2017 because in 2012, the solution temperature was much warmer at around $60^{\circ} \mathrm{C}$ compared to $34^{\circ} \mathrm{C}$ in 2017 [2].

The overall effect of adding $\mathrm{Fe}^{2+}$ with respect to gas generation is apparent. Gas generation was lower when iron was added to the solution. Even the stainless steel mesh showed lower gas generation values than samples with KI or Pt wire. Small amounts of iron may have dissolved into the acidic solution. Gas generation was lowest for the sample with the highest uranium concentration (330 g-U/L) and $100 \mathrm{ppm} \mathrm{Fe}{ }^{2+}$ added. The next lowest uranium concentration was $140 \mathrm{~g}-\mathrm{U} / \mathrm{L}$ with $100 \mathrm{ppm} \mathrm{Fe}{ }^{2+}$ added. 
Table 5. Results for LEU samples with additional catalysts irradiated at the Van de Graaff accelerator (from $1 / 25 / 17$ to $2 / 2 / 17$ ).

\begin{tabular}{|c|c|c|c|c|c|c|c|c|c|c|c|c|c|c|c|}
\hline Date & Sample Type & $\begin{array}{l}\text { U.Sulfate } \\
(g-U / L)\end{array}$ & $\begin{array}{l}\text { Sample } \\
\text { Sire (mL) }\end{array}$ & $\begin{array}{l}\text { Sample } \\
\text { Temp (C) }\end{array}$ & $\begin{array}{l}\text { Irradiation } \\
\text { Time(min) }\end{array}$ & $\begin{array}{l}\text { Average } \\
\text { Current } \\
\text { (AA) } \\
\end{array}$ & \begin{tabular}{|c|} 
Estimated \\
Total Dose \\
(Mrad) \\
\end{tabular} & \begin{tabular}{|l} 
Dose Rate \\
(Mrrad/min
\end{tabular} & $\begin{array}{l}\text { Measured } \\
\text { H202 (LM) }\end{array}$ & Precipitation & $\begin{array}{c}\mathrm{H}_{2} \\
\text { (umoles/Mrad) }\end{array}$ & $\begin{array}{c}\mathrm{O}_{2} \\
\text { (umoles/Mrad) }\end{array}$ & \begin{tabular}{|l|} 
Overall \\
HtoO \\
Ratio \\
\end{tabular} & \begin{tabular}{|l|} 
Apparent \\
Steady State \\
Time (min) \\
\end{tabular} & \begin{tabular}{|c} 
Measured H:O 0 \\
Ratio @ \\
Steady State
\end{tabular} \\
\hline $1 / 25 / 17$ & LEU & 148 & 0.5 & 41 & 299 & 6 & 13,129 & 44 & 1800 & YES & 0.062 & 0.023 & 2.7 & 80 & 2.6 \\
\hline $1 / 26 / 17$ & LEU with Pt wire & 140 & 0.5 & 36 & 334 & 5 & 12,396 & 37 & 2300 & YES & 0.054 & 0.020 & 2.7 & 120 & 3.2 \\
\hline 2/15/17 & UtSSmesh & 140 & 0.5 & 35 & 365 & 5 & 13, & 38 & 310 & YES & 0.03 & 0.013 & 2.5 & 60 & 2.4 \\
\hline $1 / 31 / 17$ & LEU with 8 mM KI & 140 & 0.5 & 35 & 359 & 5 & 13,270 & 37 & 1500 & YES & 0.049 & 0.019 & 2.7 & 66 & 2.5 \\
\hline $1 / 30 / 17$ & LEU with 100 ppm Fe Ft $^{\text {t2 }}$ & 330 & 0.5 & 33 & 254 & 5 & 8,674 & 34 & 12000 & YES & 0.016 & 0.006 & 2.5 & 40 & 2.3 \\
\hline $2 / 2 / 17$ & LEU with $100 \mathrm{ppm} \mathrm{Fe}{ }^{+2}$ & 140 & 0.5 & 35 & 352 & 5 & 12,582 & 36 & 15300 & YES & 0.024 & 0.010 & 2.4 & 72 & 2.2 \\
\hline
\end{tabular}

Gas analysis results are shown for three samples irradiated under similar conditions with dose rates of $\sim 34-44 \mathrm{Mrad} / \mathrm{min}$, solution volumes of $0.5 \mathrm{~mL}$, and temperatures of $33-41^{\circ} \mathrm{C}$. Figure 15 shows gas generation data for an LEU solution with no added catalyst, where precipitation occurred. Figure 16 shows results for a $330 \mathrm{~g}-\mathrm{U} / \mathrm{L}$ LEU solution and $100 \mathrm{ppm} \mathrm{Fe}{ }^{2+}$, and Figure 17 shows results for a $140 \mathrm{~g}-\mathrm{U} / \mathrm{L}$ LEU solution containing $100 \mathrm{ppm} \mathrm{Fe}^{2+}$.

Figure 15 shows the generation of gases and total Van de Graaff current as a function of time for the LEU sample irradiated on $1 / 25 / 17$, where a precipitate formed during irradiation. The $\mathrm{H}_{2} / \mathrm{O}_{2}$ ratio was 2.7 for this irradiation. The ratio continued to stay above two during the majority of the irradiation because $\mathrm{O}_{2}$ was being consumed as peroxide, and uranyl peroxide precipitated within the first hour of irradiation.

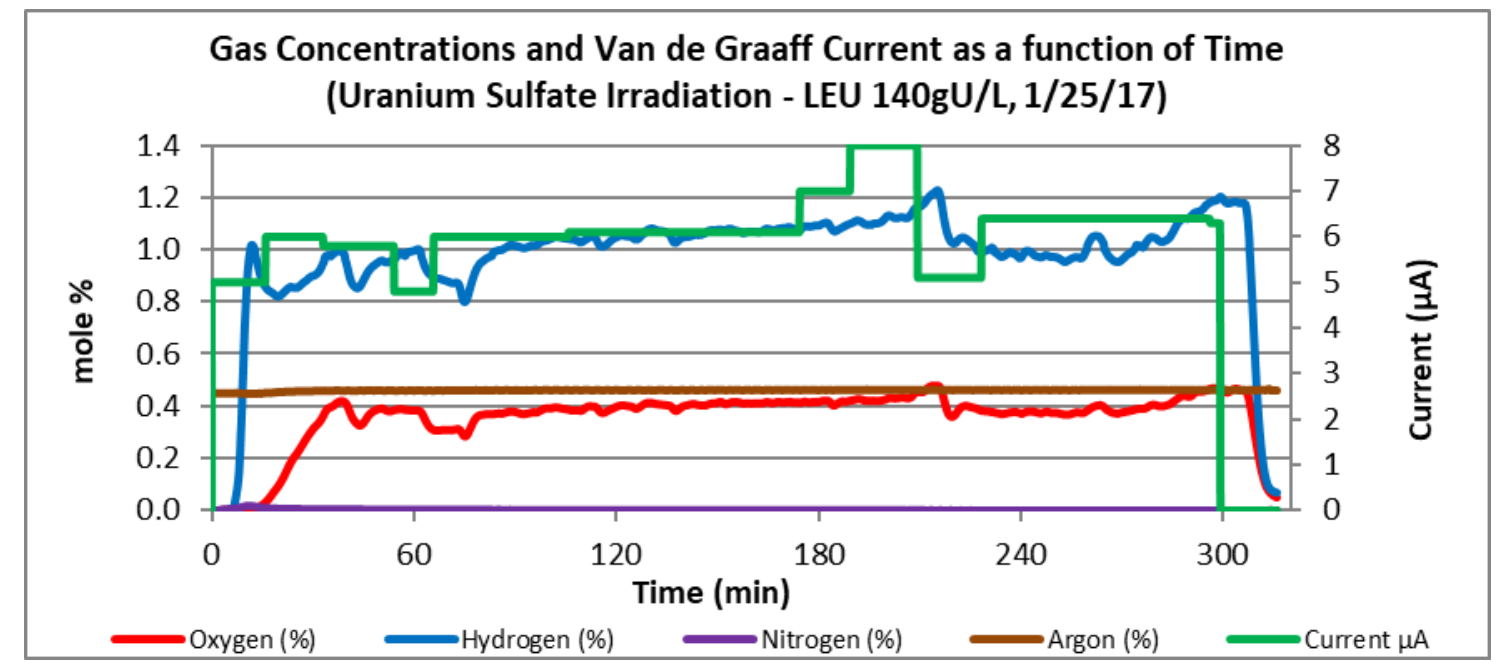

FIGURE 15. Gas generation and Van de Graaff current as a function of time for sample irradiated on $01 / 25 / 17$. 
Figure 16 shows the generation of gases as a function of total dose for the LEU sample irradiated on 01/30/17 where a precipitate formed during irradiation. The uranium concentration (330 g-U/L) was higher than in all previous samples irradiated, and $100 \mathrm{ppm} \mathrm{Fe}{ }^{2+}$ did not work to prevent precipitation. The $\mathrm{H}_{2} / \mathrm{O}_{2}$ ratio was 2.5 for this irradiation. The ratio continued to stay above two during the majority of the irradiation because $\mathrm{O}_{2}$ was being consumed as peroxide, and uranyl peroxide precipitated immediately after irradiation.

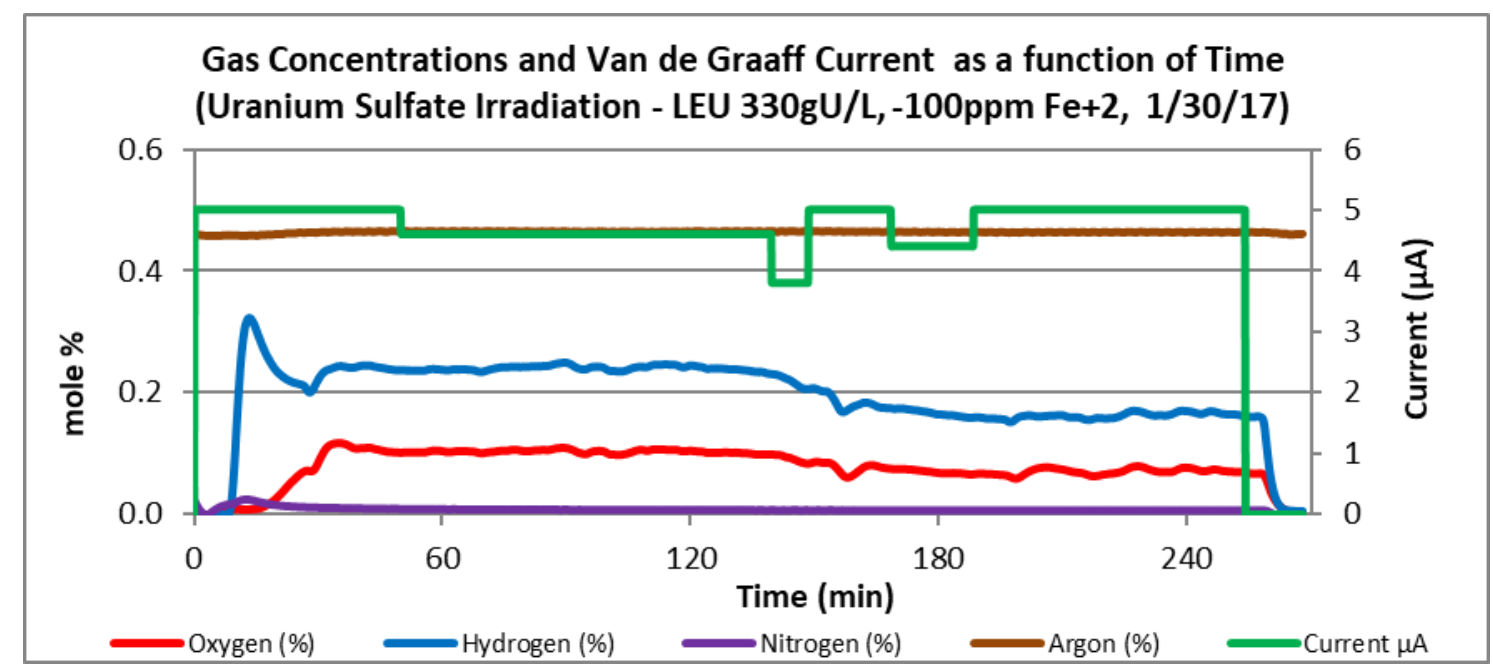

FIGURE 16. Gas generation and Van de Graaff current as a function of time for sample irradiated on 01/30/17.

Figure 17 shows the generation of gases and Van de Graaff current as a function of time for the LEU sample irradiated on $02 / 02 / 17$, where a precipitate formed during irradiation. This sample was also irradiated with $100 \mathrm{ppm} \mathrm{Fe}^{2+}$, but the uranium concentration was only $140 \mathrm{~g}-\mathrm{U} / \mathrm{L}$. Beam alignment problems were encountered during the first hour of this irradiation. The $\mathrm{H}_{2} / \mathrm{O}_{2}$ ratio was 2.4 for this irradiation. The ratio continued to stay above 2 during the majority of the irradiation because $\mathrm{O}_{2}$ was being consumed as peroxide, and uranyl peroxide precipitated within the first hour of irradiation. The amount of hydrogen and oxygen produced was higher than that for $330 \mathrm{~g}-\mathrm{U} / \mathrm{L}$. 


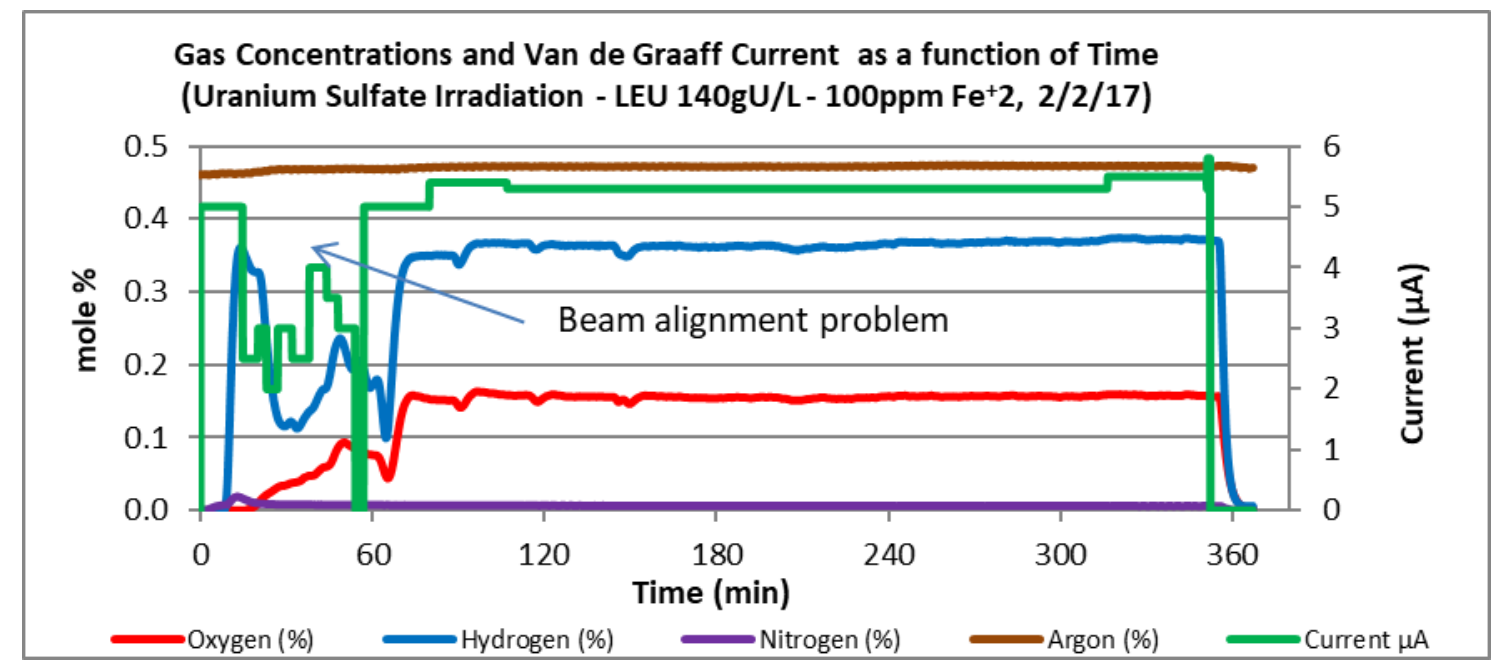

FIGURE 17. Gas generation and Van de Graaff current as a function of time for sample irradiated on $02 / 02 / 17$.

Table 6 shows LEU solutions that were irradiated at the Van de Graaff accelerator at $1 \mu \mathrm{A}$ current where solution temperatures varied between 11 and $55^{\circ} \mathrm{C}$, and the solution volume was $0.5 \mathrm{~mL}$. Irradiation times varied from 332 to 341 minutes, and the dose rates were much lower at 7-8 Mrad/min. The role of temperature was apparent in this set of irradiations because the sample irradiated on $02 / 09 / 17$ was kept at $72^{\circ} \mathrm{C}$ without the addition of a catalyst, and no precipitate formed over the course of several weeks. However, precipitation did occur in a similar sample irradiated at $21^{\circ} \mathrm{C}$ without a catalyst and in another sample that was irradiated with $100 \mathrm{ppm} \mathrm{Fe}^{2+}$ and kept at $38^{\circ} \mathrm{C}$. Temperature may play a bigger role than the addition of a catalyst for peroxide destruction, but in the current Mo-99 production design for this project, there is a large temperature gradient in the target solution vessel, so temperature cannot be the only tool used to prevent precipitation. Additionally, the sample irradiated on 2/13/17 had a pH of 1.4, compared to 1.0 for all previous samples irradiated due to literature data. This result suggests that $\mathrm{Fe}(\mathrm{III})$ catalytic destruction of peroxide is greatly controlled by $\mathrm{pH}$ [12]. The effect of $\mathrm{pH}$ was apparent because this sample was kept cold at $11^{\circ} \mathrm{C}$ with $100 \mathrm{ppm} \mathrm{Fe}{ }^{2+}$, and precipitation did not occur immediately during irradiation; however, it did form several days post-irradiation. For this project, going above a $\mathrm{pH}$ of $1.4-1.5$ is concerning because fission products will start to precipitate at $\mathrm{pH} 1.7-1.8$. The $\mathrm{H}_{2} / \mathrm{O}_{2}$ ratios were above two for all of the samples irradiated under these conditions except for the sample irradiated on 02/09/17, where precipitation did not occur. Note that the measured peroxide concentrations are artificially high for samples containing additional Fe because a complexant was not added to prevent interference from the Fe. However, precipitation did occur even at the lower dose rates of 7-8 Mrad/min and lower overall total dose applied to the samples. It took 75-190 minutes for an apparent steady state to be reached in these samples. 
TABLE 6. Additional LEU samples irradiated at the Van de Graaff accelerator (from $2 / 6 / 17$ to $2 / 13 / 17)$.

\begin{tabular}{|c|c|c|c|c|c|c|c|c|c|c|c|c|c|c|c|}
\hline Date & Sample Type & {$\left[\begin{array}{c}\text { U-Sulfate } \\
\mid g \cdot V / L L\end{array}\right]$} & $\begin{array}{l}\text { Sample } \\
\text { Size(mL) }\end{array}$ & $\begin{array}{l}\text { Sample } \\
\text { Temp ( } C \text { C) }\end{array}$ & |rradiation & $\begin{array}{c}\text { Average } \\
\text { Current } \\
(\mathrm{HA}) \\
\end{array}$ & $\begin{array}{c}\text { Estimated } \\
\text { Total Dose } \\
\text { (Mrad) } \\
\end{array}$ & $\begin{array}{l}\text { DoseRate } \\
\text { (Mrad/min) }\end{array}$ & $\begin{array}{c}\text { Measured } \mathrm{H}_{2} \mathrm{O}_{2} \\
(\mu \mathrm{M})\end{array}$ & Precipitation & $\begin{array}{c}\mathrm{H}_{2} \\
\text { (umoles/Mrad) }\end{array}$ & $\begin{array}{c}\mathrm{O}_{2} \\
\text { (umoles/Mrad) }\end{array}$ & \begin{tabular}{|l|} 
Overall \\
HtoO \\
Ratio \\
\end{tabular} & \begin{tabular}{|c|} 
Apparent \\
Steady State \\
Time (min) \\
\end{tabular} & \begin{tabular}{|c|} 
Measured H:O \\
Ratio @ \\
Steady State \\
\end{tabular} \\
\hline $2 / 6 / 17$ & LEU & 140 & 0.5 & 21 & 341 & 1.0 & 2,487 & 7 & 10800 & YES & 0.046 & 0.014 & 3.3 & 123 & 2.5 \\
\hline $2 / 9 / 17$ & $\operatorname{LEU}\left(\right.$ Hold $\left.72^{\circ} \mathrm{C}\right)$ & 140 & 0.5 & 55 & 341 & 1.0 & 2,747 & 0 & 1500 & NO & 0.012 & 0.006 & 2.0 & 75 & 2.0 \\
\hline $2 / 8 / 17$ & LEU $100 \mathrm{ppm} \mathrm{Fe}{ }^{2 t}\left(38^{\circ} \mathrm{C}\right)$ & 140 & 0.5 & 30 & 341 & 1.0 & 2,373 & 1 & 12200 & YES & 0.021 & 0.009 & 2.4 & 190 & 2.1 \\
\hline 2/13/17 & LEU $100 \mathrm{ppm} \mathrm{Fe} \mathrm{F}^{-2} \mathrm{pH} 1.4\left(11^{\circ} \mathrm{C}\right)$ & 140 & 0.5 & 11 & 332 & 0.9 & 2,258 & 1 & 3500 & Delayed & 0.011 & 0.005 & 2.2 & 180 & 2.0 \\
\hline
\end{tabular}

Figure 18 shows the generation of gases and Van de Graaff current as a function of time for the LEU sample irradiated on $02 / 06 / 17$ where a precipitate formed during irradiation. No additional catalyst was added, but the solution temperature was kept at $22^{\circ} \mathrm{C}$. The $\mathrm{H}_{2}: \mathrm{O}_{2}$ ratio was 3.3 for this irradiation. Accelerator arcs are seen at two times during this experiment. These arcs cause a temporary high power output. This causes a spike in gas generation, most notably of hydrogen.

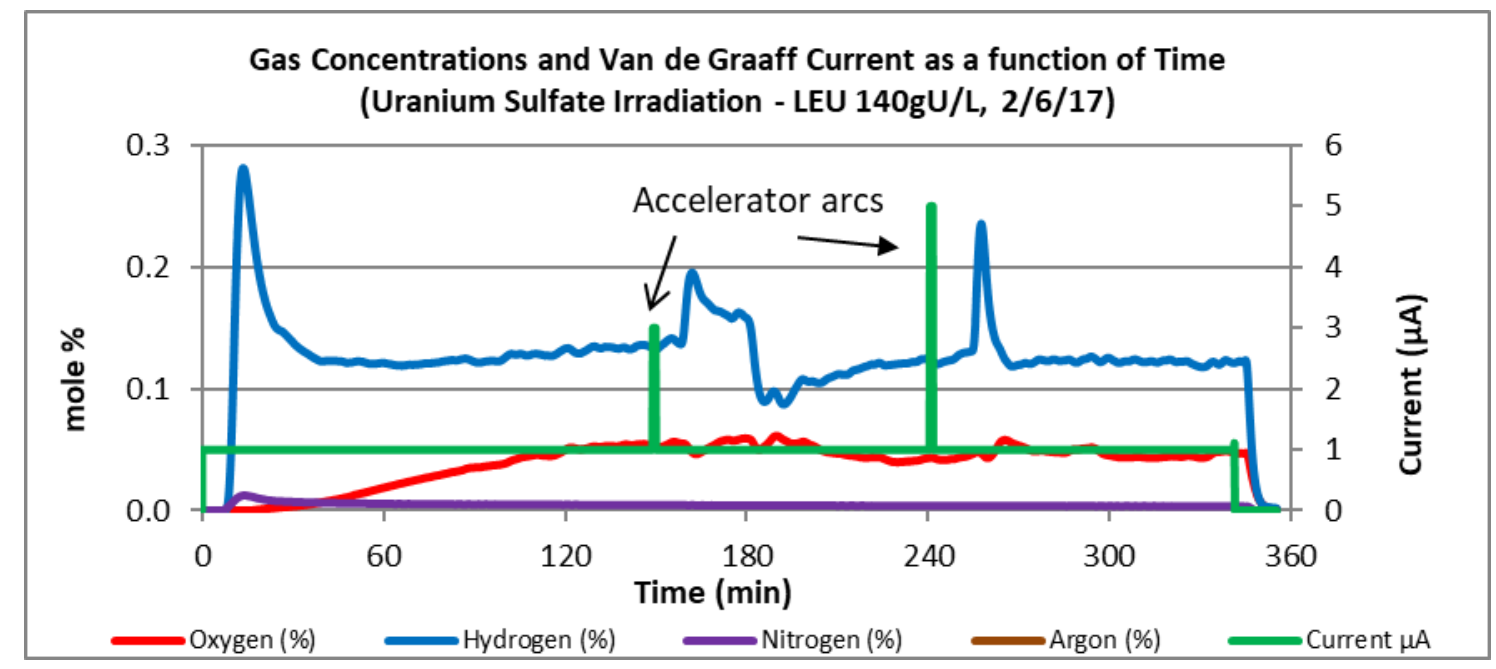

FIGURE 18. Gas generation and Van de Graaff current as a function of time for sample irradiated on 02/06/17. 
Figure 19 shows the generation of gases Van de Graaff current as a function of time for the LEU sample irradiated on 02/09/17, where a precipitate did not form during or after irradiation. No additional catalyst was added, but the solution temperature was kept at $72^{\circ} \mathrm{C}$.

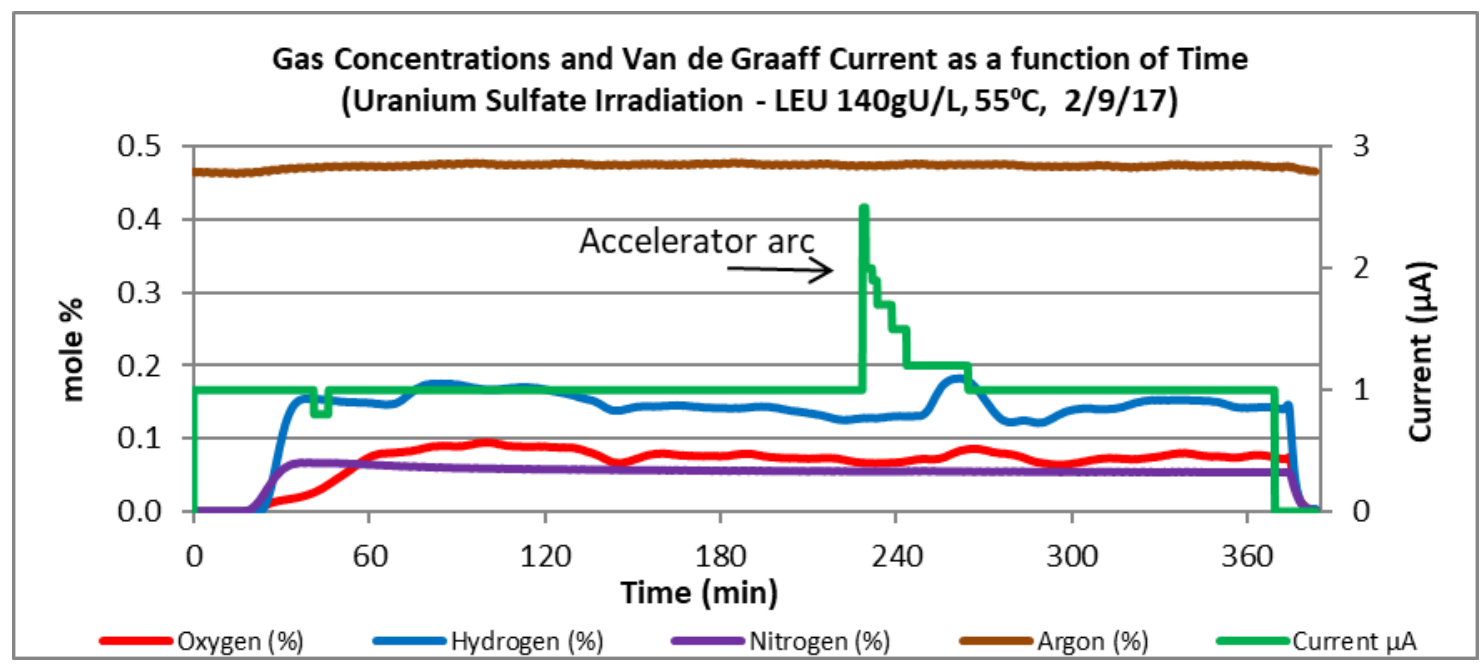

FIGURE 19. Gas generation and Van de Graaff current as a function of time for sample irradiated on 02/09/17.

Table 7 shows results for a $140 \mathrm{~g}$-U/L LEU solution irradiated for various lengths of time at $20 \mu \mathrm{A}$ current, including 10- and 120-minute samples where $1000 \mathrm{ppm} \mathrm{Fe}^{2+}$ was added. Solution temperatures were $60-78^{\circ} \mathrm{C}$, and precipitation was observed in all of these samples except for those where $\mathrm{Fe}^{2+}$ was added. This precipitation was not observed in the sample irradiated for 20 minutes until two days post-irradiation. When iron was added, there was a significant reduction in gas generation. This effect was evident throughout all of the experiments. Samples that ultimately form a precipitate showed higher productions of hydrogen and oxygen. Further study of this phenomenon could be beneficial.

TABLE 7. Timed LEU samples that were irradiated at the Van de Graaff at $20 \mu \mathrm{A}$ current (from $2 / 21 / 17$ to $2 / 28 / 17$ ).

\begin{tabular}{|c|c|c|c|c|c|c|c|c|c|c|c|c|}
\hline Date & Sample Type & $\begin{array}{c}\text { U-Sulfate } \\
(\mathrm{g}-\mathrm{U} / \mathrm{L})\end{array}$ & $\begin{array}{c}\text { Sample } \\
\text { Size }(\mathrm{mL})\end{array}$ & $\begin{array}{c}\text { Sample } \\
\text { Temp }\left({ }^{(} \mathrm{C}\right)\end{array}$ & $\begin{array}{c}\text { Irradiation } \\
\text { Time }(\mathrm{min})\end{array}$ & $\begin{array}{c}\text { Average } \\
\text { Current } \\
(\mu \mathrm{A})\end{array}$ & $\begin{array}{c}\text { Estimated } \\
\text { Total Dose } \\
(\text { Mrad })\end{array}$ & $\begin{array}{c}\text { Dose Rate } \\
(\text { Mrad/min) }\end{array}$ & Precipitation & $\begin{array}{c}\mathrm{H}_{2} \\
(\mu \mathrm{moles} / \text { Mrad })\end{array}$ & $\begin{array}{c}\mathrm{O}_{2} \\
(\mu \mathrm{moles} / \text { Mrad })\end{array}$ & $\begin{array}{c}\text { Overall } \\
\mathrm{H} \text { to O } \\
\text { Ratio }\end{array}$ \\
\hline $2 / 21 / 17$ & $10 \mathrm{~min}$ & 140 & 2 & 67 & 10 & 20 & 502 & 50 & YES & 0.090 & 0.024 & 3.7 \\
\hline $2 / 21 / 17$ & $30 \mathrm{~min}$ & 140 & 2 & 64 & 30 & 19 & 1314 & 44 & YES & 0.082 & 0.019 & 4.4 \\
\hline $2 / 22 / 17$ & $60 \mathrm{~min}$ & 140 & 2 & 61 & 60 & 17 & 2383 & 40 & YES & 0.098 & 0.031 & 3.2 \\
\hline $2 / 21 / 17$ & $120 \mathrm{~min}$ & 140 & 2 & 74 & 120 & 23 & 6217 & 52 & YES & 0.074 & 0.030 & 2.5 \\
\hline $2 / 22 / 17$ & $240 \mathrm{~min}$ & 140 & 2 & 65 & 240 & 19 & 10336 & 43 & YES & 0.111 & 0.046 & 2.4 \\
\hline $2 / 28 / 17$ & $10 \mathrm{~min} / 1000 \mathrm{ppm} \mathrm{Fe}^{+2}$ & 140 & 2 & 69 & 10 & 21 & 530 & 53 & NO & 0.004 & 0.000 & 173 \\
\hline $2 / 28 / 17$ & $120 \mathrm{~min} / 1000 \mathrm{ppm} \mathrm{Fe}^{+2}$ & 140 & 2 & 68 & 120 & 20 & 2828 & 24 & NO & 0.043 & 0.014 & 3.1 \\
\hline
\end{tabular}




\section{CONCLUSIONS}

Uranyl peroxide precipitation was observed in NU and LEU samples irradiated at the Van de Graaff accelerator. Precipitation was not observed in irradiated DU samples due to the presence of nitrate in solution whose radiolysis products are known to catalyze the destruction of peroxide [9]. It was determined that at least $200 \mathrm{ppm} \mathrm{Fe}{ }^{2+}, 250 \mathrm{ppm} \mathrm{Fe}^{3+}$, or $100 \mathrm{ppm} \mathrm{Fe}^{2+}$ with $100 \mathrm{ppm} \mathrm{Cu}^{2+}$ was needed to prevent precipitation from occurring under the given conditions. Corrosion, which adds metal ions, may take place in the Mo-99 production system, but the addition of a metal ion catalyst is necessary to prevent precipitation. Peroxide destruction increases with increasing temperature, but the significant temperature gradient expected in the Mo-99 target vessel and the fact that the solution will be stored at room temperature while not being irradiated prevent using temperature as a means to combat precipitation. The effectiveness of $200 \mathrm{ppm}$ of a metal ion will be tested as part of the upcoming mini-AMORE experiments.

Initial radiolysis displayed an immediate spike in hydrogen and hydrogen peroxide, as indicated by the gas analysis and ultraviolet-visible spectroscopy results from the short irradiations. Oxygen levels rose later in the irradiation compared to hydrogen, which is attributed to the formation of hydrogen peroxide as well as other reactions in solution. After 25 minutes (shortest time for apparent steady state to be reached in a DU sample irradiated on 12/06/16) to 291 minutes (longest time for steady state to be reached in an LEU sample irradiated on 03/09/17 with $500 \mathrm{ppm} \mathrm{Cu}^{2+}$ ), the ratios of hydrogen to oxygen eventually stabilized.

Total hydrogen and oxygen production was found to be dependent on the solution composition. Figure 20 shows three different irradiations. The parameters were nearly identical for all samples, but they show quite dramatic differences in gas generation behavior. For the 12/15/16 experiment with LEU alone (Figure 20 left), oxygen does not come out of solution until about 10 minutes into the irradiation. Total gas production was $\mathrm{H}_{2}=0.135$ and $\mathrm{O}_{2}=0.054$ $\mu$ moles/Mrad. For the 3/8/17 experiment with LEU $+500 \mathrm{ppm} \mathrm{Fe}^{2+}$ (Figure 20, middle), oxygen does not come out of solution until slightly later, approximately 17 minutes into the irradiation. Total gas production was also significantly lower: $\mathrm{H}_{2}=0.039$ and $\mathrm{O}_{2}=0.017 \mu \mathrm{moles} / \mathrm{Mrad}$. For the 3/2/17 experiment with LEU $+1000 \mathrm{ppm} \mathrm{Fe}^{2+}$ (Figure 20, right), oxygen comes out of solution even later, approximately 20 minutes into the irradiation. Total gas production was the lowest in this sample, with $\mathrm{H}_{2}=0.025$ and $\mathrm{O}_{2}=0.010 \mu \mathrm{moles} / \mathrm{Mrad}$. This finding shows that the addition of the peroxide catalyst $\left(\mathrm{Fe}^{2+}\right)$ will decrease the total gas production. It may also lengthen the time it takes for oxygen evolution. The scavenging of electrons by $\mathrm{Fe}^{3+}$ may be attributed to this phenomenon, but more work is needed to prove this inference. The delay in oxygen generation cannot be fully described by its solubility in the solution, since for water at $30^{\circ} \mathrm{C}$, the solubility is only about $7.56 \mathrm{mg} / \mathrm{L}$. It may be due, in part, to a lower peroxide generation from the scavenging of electrons. This could also indicate that the primary source of molecular oxygen is due to the decomposition of hydrogen peroxide. 


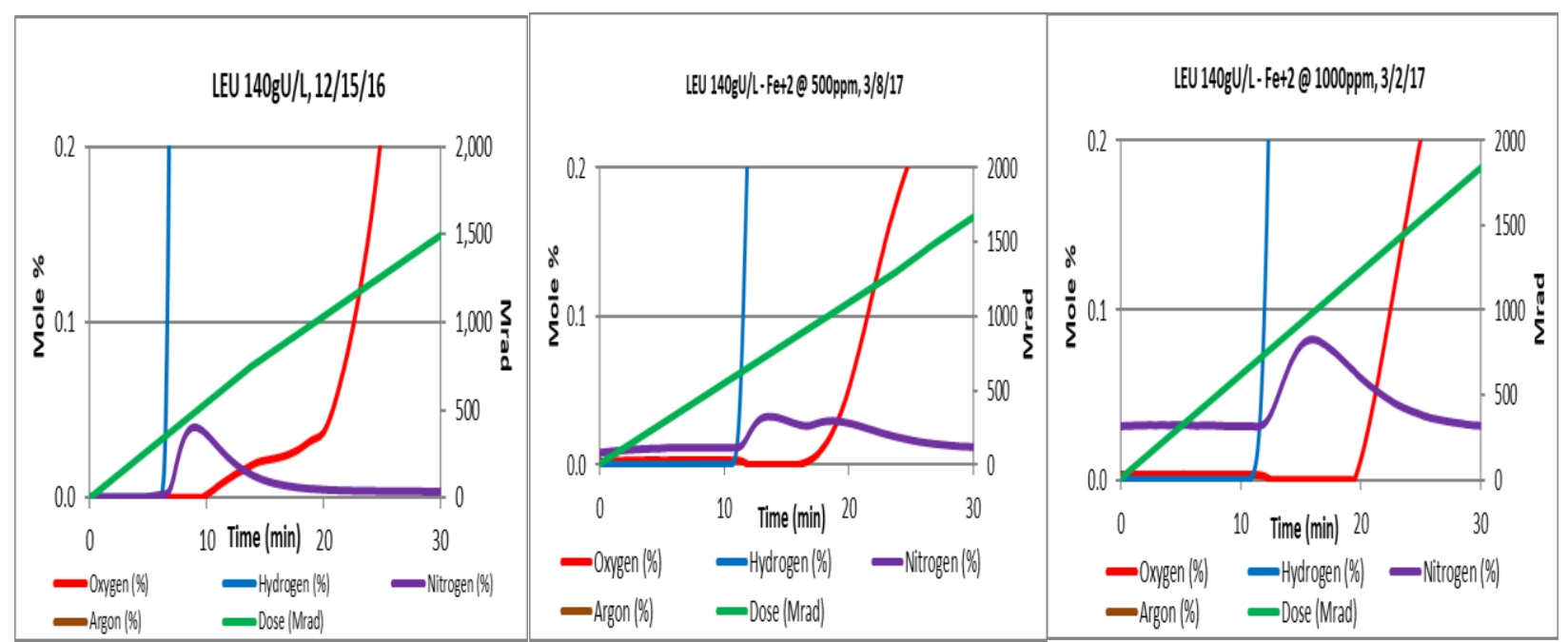

FIGURE 20. Initial gas production of solutions with different composition.

\section{REFERENCES}

[1] Kalensky, M., Chemerisov, S., Youker, A., Hebden, A., Tkac, P., Makarashvili, V., Krahn, E., Krebs, J., Quigley, K., Lowe, R., Bowers, D., Niak, S., Graczyk, D., Sullivan, V., Bakel, A., and Vandegrift, G.F., "Radiolysis of Nitrate and Sulfate Solutions," Argonne National Laboratory Report ANL/CSE-13/23 (November 20, 2012).

[2] Kalensky, M., Chemerisov, S., Youker, A., Tkac, P., Krebs, J., Quigley, K., Lowers, R., Bakel, A., and Vandegrift, G. F., "Means to Eliminate Uranyl Peroxide Precipitation in SHINE Target Solution," Argonne National Laboratory Report ANL/CSE-13/21 (March 14, 2013).

[3] Youker, A.J., Jerden, J., Kalensky, M., Quigley, K., Jonah, C., Chemerisov, S., and Vandegrift, G.F., "Peroxide Formation, Destruction, and Precipitation in Uranyl Sulfate Solutions: Simple Addition and Radiolytically Induced Formation," ANL/CSE-14/35 (October 2014).

[4] Silverman, M.D., Watson, G.M., and McDuffie, H.F., "Peroxide Decomposition in Aqueous Homogeneous Reactor Fuels," Indust. Eng. Chem., 8: 1238-1241 (1956).

[5] Youker, A., Chemerisov, S., Tkac, P., Bowers, D., Kalensky, M., and Vandegrift, G.F. "A Solution-Based Approach for Mo-99 Production: Considerations for Nitrate versus Sulfate Media,” Sci. Technol. Nucl. Install., Vol. 2013: 402570 (2013).

[6] Sunil, K., and Narayana, B., "Spectrophotometric Determination of Hydrogen Peroxide in Water and Cream Samples," Bull. Environ. Contam. Toxicol. 81: 422-426 (2008).

[7] Draganic, I., "Oxalic Acid: The Only Aqueous Dosimeter for In-Pile Use," Nucleonics 21(2): 33 (1963). 
[8] Salit, M.L, Turk, G.C., Lindstrom, A.P., Butler, T.A., Beck II, C.M. and Norman, B., "Single-Element Solution Comparisons with a High-Performance Inductively Coupled Plasma Optical Emission Spectrometric Method," Anal. Chem. 73: 4821-4829 (2011).

[9] Bhattacharyya, P.K., and Saini, R.D., "Radiolytic Yields $\mathrm{G}\left(\mathrm{HNO}_{2}\right)$ and $\mathrm{G}\left(\mathrm{H}_{2} \mathrm{O}_{2}\right)$ in the Aqueous Nitric Acid System," Int. J. Radiat. Phys. Chem. 5: 91-99 (1973).

[10] Haber, F., and Weiss, J., "The Catalytic Decomposition of Hydrogen Peroxide by Iron Salts," Proc. Royal Soc. A, 147: 332 (1934).

[11] de Laat, J., and Gallard, H., "Catalytic Decomposition of Hydrogen Peroxide by Fe(III) in Homogeneous Aqueous Solution: Mechanism and Kinetic Modeling," Environ. Sci. Technol. 33 (16), 2726-2732 (1999).

[12] De Laat, J., and Gallard, H., "Catalytic Decomposition of Hydrogen Peroxide by Fe(III) in Homogeneous Aqueous Solution: Mechanism and Kinetic Modeling," Environ. Sci. Technol. 33: 2726-2732 (1999).

[13] Spinks, J.W.T., and Woods, R.J., Introduction to Radiation Chemistry, J. Wiley and Sons, New York (1990). 
This page intentionally left blank. 



\section{Argonne}

Nuclear Engineering Division

Argonne National Laboratory

9700 South Cass Avenue, Bldg. 208

Argonne, IL 60439-4854

www.anl.gov 